Research Article

\title{
Analysis of Rock $\beta$-Dynamic Parameters and the Stability of Earthquake Dangerous Rocks Based on PFC
}

\author{
Yun Tian $\mathbb{D},{ }^{1}$ Lin-feng Wang $\mathbb{D},{ }^{1}$ Biao Zeng $\mathbb{D},{ }^{2}$ and Hong-hua Jin $\mathbb{D}^{2}$ \\ ${ }^{1}$ Key Laboratory of Geological Hazards Mitigation for Mountainous Highway and Waterway, \\ Chongqing Municipal Education Commission, Chongqing Jiaotong University, Chongqing 400071, China \\ ${ }^{2}$ School of Transportation, Southeast University, Nanjing 210096, China \\ Correspondence should be addressed to Lin-feng Wang; wanglinfeng@cqjtu.edu.cn
}

Received 11 October 2020; Revised 20 November 2020; Accepted 26 November 2020; Published 9 December 2020

Academic Editor: Zhi Cheng Tang

Copyright (C) 2020 Yun Tian et al. This is an open access article distributed under the Creative Commons Attribution License, which permits unrestricted use, distribution, and reproduction in any medium, provided the original work is properly cited.

\begin{abstract}
Mesoparameters of rock materials are the main factors affecting the macromechanical properties of dangerous rock slopes. Based on the principle of particle flow and synthetic rock mass technology (SRM), the influence of mesoparameters on macromechanical properties is investigated by calibrating mesoparameters of rock materials at depth for a rock sequence in Beichuan Qiang Autonomous County, Sichuan Province, China. By combining these parameters with conventional and dynamic cycle triaxial tests, sensitivity analysis of rock $\beta$-parameters was completed. As a result, the reliability of mesoparameters in the simulation of dangerous rocks is strengthened, providing a basis to examine the failure mechanism of earthquake dangerous rocks in this region. Results indicate that, in the triaxial test, sandstone failed in tension, and brittleness gradually weakened as confining pressure increased. Mudstone recorded shear failure, and the characteristic value of brittle attenuation showed a V-shaped change with increasing confining pressure. Under cyclic loading, cracks had a degrading effect on the damping ration $(\beta)$ and the damping coefficient $(C)$ of sandstone. Mudstone recorded relatively low $\beta$ and low brittleness whilst sandstone had high $\beta$ and high brittleness. In rock materials, $\beta_{n}$ is more sensitive than $\beta_{s}$ in mechanical properties. When the value of the $\beta_{n}$-parameter was between 0.2 and 0.3 and the value of the $\beta_{s}$-parameter was between 0.2 and 0.6 , rock brittleness was more stable, and the reflected macroscopic mechanical properties were the most authentic. By using a deepened mesoparameter trial adjustment method, the failure mode of the Particle Flow Code (PFC) dangerous rock model near provincial highway 205, simulated under conditions for the Wenchuan earthquake, indicated a tensile fracture-horizontal slip failure. The simulated failure mode was consistent with that of real dangerous rocks, with the failure trend being concentrated between the first and the third layer of the rock mass.
\end{abstract}

\section{Introduction}

Sichuan Province, China, located in the Helan-LiupanLongmen-Hengduan Mountain seismic zone, experiences frequent earthquakes and rockslides. In this area, earthquake-induced rock slope instability often occurs, resulting in significant economic and property loss. Dangerous rock slopes have been identified as the main formation resulting in earthquake-type slope collapse disasters. Rock masses are generally cut by different structural planes. When the main control structural plane is located at the rear of the dangerous rock block, it gradually penetrates the rock mass until the mass breaks under the action of multiple factors. Under this condition, the dangerous rock block becomes unstable and is destroyed. Although previous investigations have predominantly examined instability and failure of dangerous rocks, studies examining the stability of dangerous rocks in earthquake areas are typically based on the principle of particle flow; reliable rock material mesoparameter calibration methods are urgently needed. This area of research has become one of the main research areas and technical challenges in this field $[1,2]$. From the perspective of rock materials, the discrete element method has become important to solve critical rock simulation technology, and the key condition to determine the reliability of the method is the selection of mesoparameters in the model.

For seismic slopes, Chen [3] deduced the chain development process of dangerous rocks in the Three Gorges 
Reservoir area. From the perspective of geomorphology, they revealed the influence of rock cavern weathering on the stability of dangerous rock slopes, proposing the dangerous rock chain pattern development. Based on fracture mechanics and damage mechanics, Tang et al. [4, 5] discussed the sequence of dangerous rock caving on a cliff with a weak base, establishing a calculation method for the time of dangerous rock caving. Yan et al. [6] used the QUIVER code to realize the response analysis of earthquake gentle slopes, identifying slope response and sliding displacement law under the action of an earthquake. The movement characteristics of dangerous rock slopes under different seismic conditions were simulated by Huang et al. [7] using the discontinuous deformation analysis (DDA) method. The influence of seismic loads on the movement characteristics of dangerous rock mass collapse blocks was shown using the DDA method. Zhao et al. [8] used particle flow PFC2D software to dynamically simulate the instability process of rock slopes, revealing the influence of the distribution of weak structural planes on the instability and failure of rock slopes. Tang et al. [9] used a two-dimensional discrete element simulation to study the formation mechanism of the Caoling landslide in 1941.

For studies of rock materials, Cong et al. [10] proposed that the macroscopic mechanical characteristics of materials are closely related to microscopic parameters. These parameters can be combined with marble indoor loading and unloading tests to determine the mesoparameters suitable for rock materials (such as marble). He et al. [11] comparatively analyzed the damping characteristics of sandstone, conglomerate, and glutenite under different stress paths, highlighting the evolution of the damping ratio $(\beta)$ and the damping coefficient $(C)$ with the number of cycles. The influence of fractures on rock mechanical properties proposed by Huang et al. [12] has important practical significance for the engineering stability of fractured rock masses. In addition, strength, deformation parameters, and failure modes of rock materials with discontinuous, nonparallel double fissures were analyzed in detail. The mesoparameters of PFC2D numerical sandstone samples from the mesolevel aspects of displacement, crack evolution, and distribution were studied by Zhou et al. [13]. Tang and Zhang [14-16] studied the shear behavior of rock fractures from the perspective of temperature and provided new ideas for the stability evaluation of surrounding rock in temperature-dependent underground engineering. Tang and Jiao [17] also proposed that, in the contact behavior of rock joints, the three-point peak (3PP) standard seems to be the most appropriate method to identify the contour peaks of rock joints. Zou et al. [18] used the extended finite element method (XFEM) to simulate the propagation of hydraulic fractures in heterogeneous reservoirs. They proposed that the hard blocks in the reservoir promote the growth of hydraulic fractures, but limit the growth of fracture widths.

As the majority of previous investigations considered the two-dimensional particle flow method, dangerous rock slope simulation technology lacks reliability due to insufficient factors being considered, resulting in low applicability of earthquake dangerous rock simulation technology in earthquake areas. Furthermore, the mechanical characteristics and mesoscopic parameters of rock materials need further evaluation. In particle flow rock material simulation, the parallel bond contact model is generally used to assign values to the contact between rock particles. Since Poisson's ratio $\mu$, elastic modulus $E^{*}$, stiffness ratio $k^{*}$, and other mesoparameters will directly affect the macromechanical properties of rock materials under numerical tests, they have become the main objects considered in the trial adjustment processes [19-25]. However, under the dynamic action of a rock slope, the damping ratio $(\beta)$ is an important parameter that affects the dynamic response of a rock [11]. This influence on the macromechanical properties of rock materials has generally been overlooked in previous investigations. Therefore, our study includes crack tracking, strength attenuation index (brittleness characteristics), and $\beta$-dynamic parameter analysis on the basis of traditional parameter adjustment methods. By selecting different mesoparameters from previous studies, we investigated normal critical damping ratio $\beta_{n}$ and shear critical damping ratio $\beta_{s}$ for sensitivity analysis. As a result, rock mesoparameters that can better reflect true materials are obtained, providing a strong basis for simulating the seismic damage of dangerous rocks and analyzing the stability of earthquake dangerous rocks.

\section{Mechanical Behavior of Rock Materials}

\subsection{Sample Equipment and Sample Preparation}

2.1.1. Sample Equipment. Mudstone and sandstone mechanical tests in this study were performed on a RMT-150C rock mechanics test system (Figure 1) which can realize automatic data collection and processing. The maximum axial load of the testing machine is $1000 \mathrm{kN}$, the vibration frequency is $0.2-2 \mathrm{~Hz}$, the specimen size is $\Phi$ $(50 \times 100)-(100 \times 300) \mathrm{mm}$, the maximum three-axis confining pressure is $100 \mathrm{MPa}$, the confining pressure rate is $0.001-1 \mathrm{MPa} / \mathrm{s}$, the displacement measurement range is $\pm 50 \mathrm{~mm}$, and the strain measurement range is \pm 0.01 . The source vibration wave can be sine wave, triangle wave, square wave, oblique wave, etc.

2.1.2. Sample Preparation. One set of mudstone and three sets of sandstone (Figure 2) were used in this investigation. The static mechanics test was divided into one set of mudstone specimens (No. A) and one set of sandstone specimens (No. B). The dynamic test was divided into one group of conventional sandstone specimens (No. C) and one group of fractured sandstone specimens (No. D) (Figure 3). Rock samples were collected from dangerous rock on Provincial Highway 205 in Beichuan Qiang Autonomous County. The test sample was a cylinder with a diameter of $50 \mathrm{~mm}$ and a height of $100 \mathrm{~mm}$. The error range was controlled within $\pm 2 \mathrm{~mm}$, meeting the requirement of a $2: 1$ height-to-diameter ratio specified by the International Society of Rock Mechanics. The cutting position of the cracked sandstone was set as the top central axis; the cutting depth was $50 \mathrm{~mm}$, and the gap width was $2 \mathrm{~mm}$. 


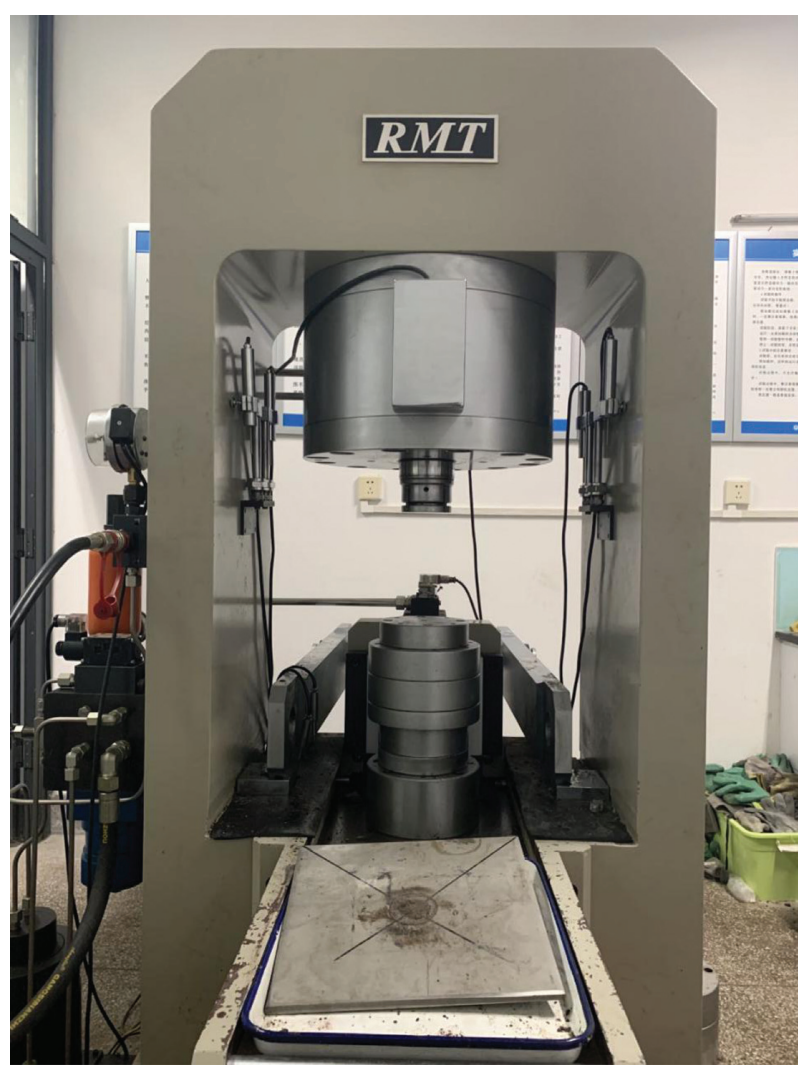

FIgURE 1: The RMT-150C rock mechanics test system.
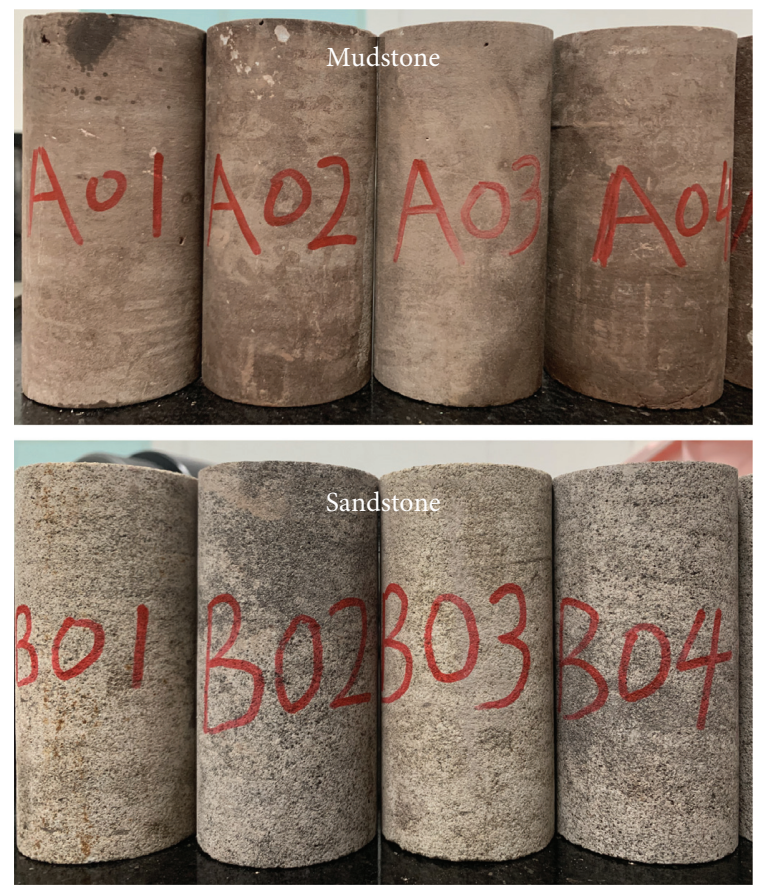

Figure 2: Conventional triaxial rock specimens.

\subsection{Mechanics Test Plan}

2.2.1. Conventional Triaxial Test. The conventional triaxial test is an important step for adjusting the mesoparameters of PFC3D and determining the rationality of the particle flow

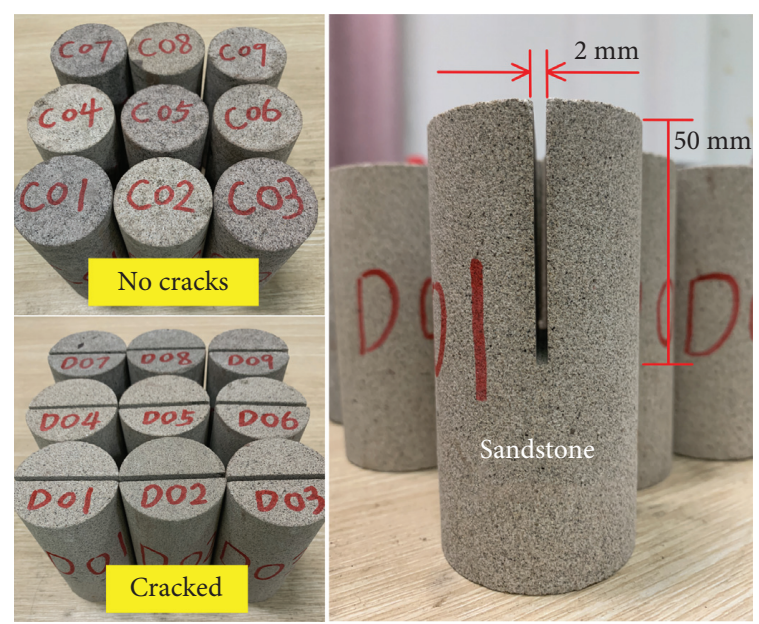

Figure 3: Triaxial circulation sandstone samples.

method. This test was carried out at a room temperature of about $25^{\circ} \mathrm{C}$. The loading test adopts axial strain control; the loading rate was $0.02 \% / \mathrm{min}$, the maximum stress was set to $150 \mathrm{kN}$, and the axial load was continuously applied under four confining pressures (2 $\mathrm{MPa}, 4 \mathrm{MPa}, 6 \mathrm{MPa}$, and $8 \mathrm{MPa}$ ) until the rock sample failed. The strength criterion of the conventional triaxial test followed the Mohr-Coulomb strength criterion $[26,27]$. The failure mechanism was that the material experiences shear failure under the action of normal stress. The maximum shear stress $\tau_{m}$ it bears was determined by the cohesion and the angle of internal friction, expressed as

$$
\tau_{m}=c+\sigma \tan \varphi,
$$

where $c$ is the cohesive force, $\sigma$ is the normal stress on the shear failure surface, and $\varphi$ is the internal friction angle. In order to further reflect the brittleness of the rock, we examined the mechanical index that characterizes the strength attenuation behavior of rock samples after the peak [28]. The specific algorithm was as follows:

$$
\begin{aligned}
& D_{s}=\frac{\sigma_{1}^{P}-\sigma_{r}}{\sigma_{1}^{P}}=\frac{\Delta \sigma}{\sigma_{1}^{P}}, \\
& \Delta \sigma=\sigma_{1}^{P}-\sigma_{r},
\end{aligned}
$$

where $D_{s}$ is the intensity attenuation coefficient and the value range is $[0,1] ; \Delta \sigma$ is the intensity attenuation value; $\sigma_{1}^{P}$ is the peak intensity; and $\sigma_{r}$ is the residual intensity.

2.2.2. Dynamic Cycle Triaxial Test. The dynamic cycle triaxial test was used to study the dynamic mechanical characteristics of the rock samples under three-dimensional stress. The test simulates not only the static stress state of the rock on-site, but also the actual seismic effect. This test provides a reference for studying the dynamic parameters of sandstone and the dynamic stability of dangerous rocks. In the cyclic loading process of an ideal elastic material, the stress and strain time history of the elastic body is synchronized. Rock is a typical inhomogeneous material, with 
different levels of cracks, pores, and other microscopic defects distributed throughout. The cement interface between mineral particles is also a relatively weak surface. The area of the hysteresis loop can reflect the amount of energy consumed in the cyclic loading process. Under ideal elasticity, the vibration damping ratio $\beta$ can be calculated according to the area of the hysteresis loop; the average slope of the hysteresis loop reflects the magnitude of the dynamic elastic modulus $E_{d}$ (Figure 4) [29].

The values of damping ratio $\beta$, damping coefficient $C$, and $E_{d}$ can be calculated as follows [30]:

$$
\begin{gathered}
\beta=\frac{A}{\left(4 \pi / A_{s}\right)}, \\
C=\frac{A}{\pi X^{2} \omega}, \\
E_{d}=\frac{\sigma_{d \max }}{\varepsilon_{d \max }},
\end{gathered}
$$

where $A$ is the area of the hysteresis loop $\mathrm{ABCDA} ; A_{s}$ is the area of triangle AOE; $X$ is the amplitude of vibration; $\omega$ is the angular frequency of vibration; $\sigma_{d \max }$ is the maximum axial dynamic stress of the hysteresis loop; and $\varepsilon_{d \max }$ is the maximum axial dynamic strain of the hysteresis loop. As dangerous rocks in this area are mainly composed of sandstone, this cyclic test was only conducted on sandstone samples. Confining pressures were $2 \mathrm{MPa}, 4 \mathrm{MPa}$, and $6 \mathrm{MPa}$, and the vibration frequency was $1 \mathrm{~Hz}$; the loading rate was $60 \mathrm{kN} / \mathrm{min}$. The loading process was divided into six stages of cyclic loading: (1) when the hoop load reached the predetermined confining pressure, the first stage was loaded from 0 to $20 \mathrm{kN}$ and then loaded cyclically between 0 and $20 \mathrm{kN}$ at a frequency of $1 \mathrm{~Hz} 30$ times and then unloaded to 0 . (2) The second stage was loaded from 0 to $40 \mathrm{kN}$, loaded cyclically from 0 to $40 \mathrm{kN}$ at a frequency of $1 \mathrm{~Hz} 30$ times, and finally unloaded to 0 . Stages 3 to 6 continued in this format until $120 \mathrm{kN}$ was used in stage 6. During the step-bystep loading process, if the test piece was damaged, the test ended.

\subsection{PFC Mechanical Test}

2.3.1. Numerical Three-Axis Servo Test. In this study, the PFC3D simulated triaxial test was used to conduct microscopic failure analysis and mesoparameter calibration on two kinds of rocks. The entire three-axis numerical simulation loads the sample by specifying the top and bottom wall boundary constraint speeds, determining the stress and strain state of the sample through the built-in FISH function of PFC3D. The established loading model is shown in Figure 5. According to the real triaxial test, the model generates particles in a cylindrical wall with a height of $10 \mathrm{~m}$ and a diameter of $5 \mathrm{~m}$. In preliminary model calculations, it was found that if the particles are generated according to the actual gradation, the number of particles will reach 1 million. However, the existing calculation conditions cannot complete the numerical analysis of such a large number of

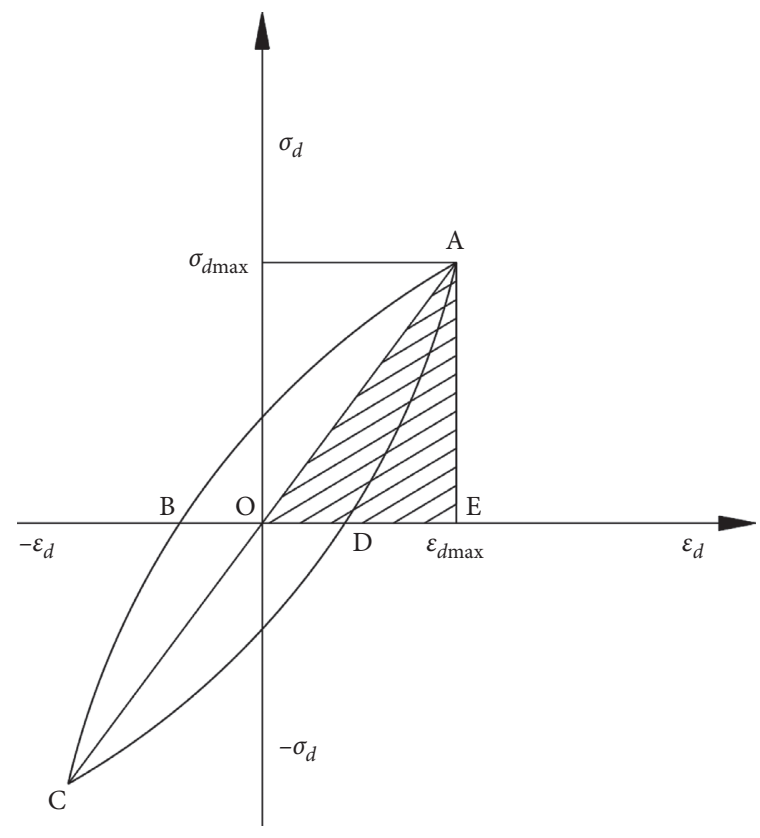

FIgURE 4: Dynamic stress-strain hysteresis loop.

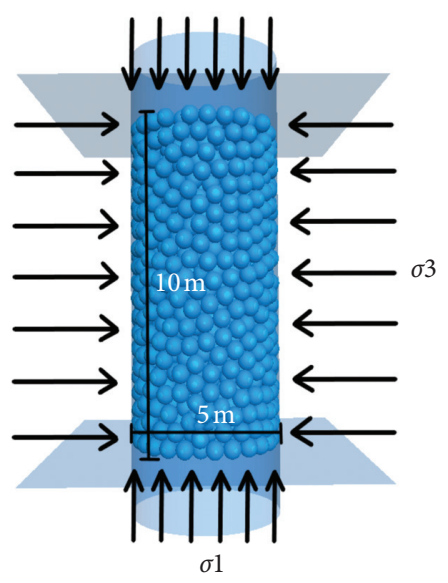

FIGURE 5: Schematic diagram of the numerical three-axis loading model.

particles. In this case, after considering the impact of the particle size effect on the test results [31], the radius of the particles is appropriately expanded, and the radius is $0.2-0.25 \mathrm{~m}$. The purpose of setting the sample size in this way is to keep the particle size of the numerical triaxial sample and the numerical slope model at the same size (that is, the unit is $\mathrm{m}$ ). At the same time, it not only improves the calculation efficiency, but also does not affect the accuracy of the simulation results. Under the condition of constant confining pressure, the upper and lower loading plates moved towards each other at a speed of $10 \mathrm{~mm} / \mathrm{min}$ until the specimen was broken. The stress-strain curve was automatically recorded throughout the process. In addition, the confining pressure was loaded according to the amount of $2 \mathrm{MPa}, 4 \mathrm{MPa}, 6 \mathrm{MPa}$, and $8 \mathrm{MPa}$ in the indoor test. Finally, the overall project view and flowchart of the analysis steps is shown in Figure 6. 


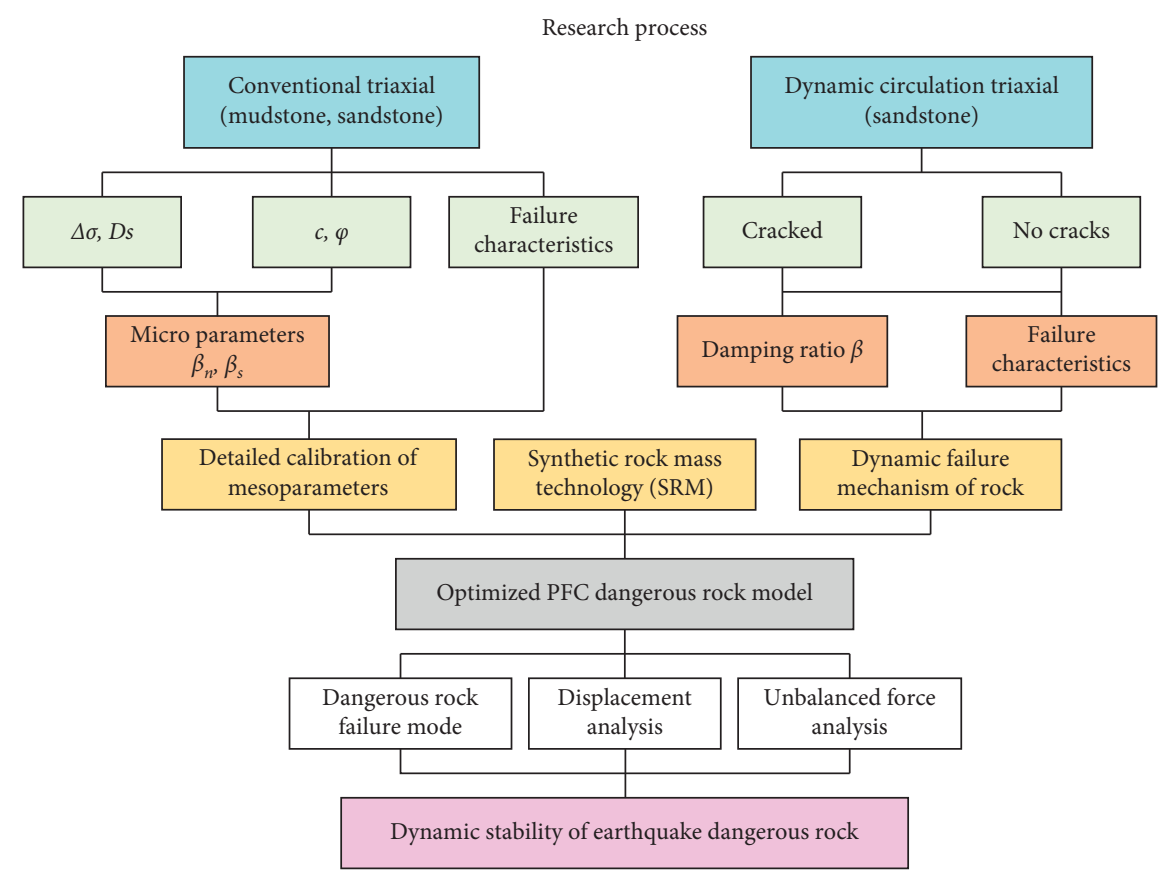

Figure 6: Research flowchart.

\subsection{Mechanical Test Analysis}

2.4.1. Conventional Triaxial Test Analysis. The macromechanical properties of sandstone and mudstone under the two triaxial test methods are shown in Table 1. Comparison of results under the two methods indicates that cohesion $c$ and the friction angle $\varphi$ were essentially consistent. Among these, the cohesive force error was controlled within $0-0.02 \mathrm{MPa}$, and the friction angle error was controlled within $0.3^{\circ}-0.4^{\circ}$, thereby preliminarily determining the rationality of the microscopic parameters.

In the process of the numerical triaxial test, the damaged contact links were expressed in the form of disc joints (DNF_disk), thereby forming damage cracks. The change law of strength attenuation value $\Delta \sigma$, strength attenuation coefficient $D_{s}$, and failure characteristics of the two rock samples is shown in Figure 7. With an increase of confining pressure, $\Delta \sigma$ for sandstone recorded a gradual trend of decrease, consistent with the findings of Zuo et al. [26]. The $D_{s}$ curve for sandstone recorded an obvious sharp decline (0.67 to 0.37 ) after a confining pressure of $2 \mathrm{MPa}$, after which the decline continued more slowly. This result indicates that the brittleness of sandstone gradually weakens with an increase of confining pressure, and the weakening ability of brittleness increases after a confining pressure of $2 \mathrm{MPa}$ is reached. $\Delta \sigma$ and $D_{s}$ mudstone curves recorded a $\mathrm{V}$-shaped change with increasing pressure (Figure $7(\mathrm{~b})$ ). When the curve dropped to a $4 \mathrm{MPa}$ confining pressure, $\Delta \sigma$ and $D_{s}$ increased at the same time, by $7.05 \mathrm{MPa}$ and 0.15 , respectively; after $6 \mathrm{MPa}$, the rate of increase declined. This result indicates that, under a low confining pressure, due to large initial porosity, the brittleness of mudstone initially weakens and ductility is enhanced. Mudstone brittleness then increases, and ductility decreases at a high confining pressure.
Finally, the difference in $\Delta \sigma$ and $D_{s}$ between the two rocks is due to the difference in initial porosity and initial pore water content between sandstone and mudstone. It can be said that, under the same external conditions, the strength of mudstone is generally smaller than that of sandstone, and the initial porosity and initial pore water ratio are also greater than those of mudstone. Therefore, when the confining pressure of mudstone continues to increase, the pores will be compacted in the middle, the pore water will be discharged, and a new arrangement and combination of rock particles will be formed inside the rock. This makes the strength decay curve different from sandstone.

Analysis of the partial failure characteristics of the two rock samples shows that the failure mode of sandstone is a tensile failure; mudstone has a shear failure. There were numerous tensile cracks in the microscopic joints of the sandstone, with tensile fractures causing the main damage among individual grains. When the confining pressure was $2 \mathrm{MPa}$, mesocracks were generated from the bottom of the sandstone which gradually developed towards the top. Due to the low confining pressure, macroscopic shear cracks did not penetrate the top, and the top mesocracks developed slowly. When the confining pressure was $8 \mathrm{MPa}$, the bottom crack gradually expanded to the top, forming a penetrating macroscopic shear crack. The sandstone samples failed under this confining pressure; the number of cracks gradually increased as the confining pressure increased, finally forming rock failure characterized by a multiple crack staggered development. Mudstone specimens mostly recorded shear cracks in the microscopic joints, with the majority of fractures occurring between particles being shear failures. Under a confining pressure of $2 \mathrm{MPa}$, a single shear failure was recorded for the mudstone, 
TABle 1: Comparison of rock mechanics characteristics.

\begin{tabular}{|c|c|c|c|c|c|c|c|}
\hline & Method & $\sigma 3(\mathrm{MPa})$ & $\sigma 1-\sigma 3(\mathrm{MPa})$ & $\sigma 1(\mathrm{MPa})$ & $\sigma r(\mathrm{MPa})$ & $c(\mathrm{MPa})$ & $\varphi\left({ }^{\circ}\right)$ \\
\hline \multirow{8}{*}{ Mudstone } & \multirow{4}{*}{ Test } & 2 & 9.3 & 11.3 & 3.2 & \multirow{4}{*}{1.32} & \multirow{4}{*}{32.53} \\
\hline & & 4 & 13.95 & 17.95 & 10.36 & & \\
\hline & & 6 & 19.46 & 25.46 & 11.28 & & \\
\hline & & 8 & 24.06 & 32.06 & 13.55 & & \\
\hline & \multirow{4}{*}{ PFC } & 2 & 11.52 & 13.66 & 3.98 & \multirow{4}{*}{1.35} & \multirow{4}{*}{32.81} \\
\hline & & 4 & 14.18 & 18.18 & 11.28 & & \\
\hline & & 6 & 19.81 & 25.81 & 12.41 & & \\
\hline & & 8 & 23.97 & 31.97 & 14.09 & & \\
\hline \multirow{8}{*}{ Sandstone } & \multirow{4}{*}{ Test } & 2 & 41.31 & 43.31 & 15.00 & \multirow{4}{*}{8.14} & \multirow{4}{*}{38.42} \\
\hline & & 4 & 47.41 & 51.41 & 31.61 & & \\
\hline & & 6 & 53.86 & 59.86 & 41.79 & & \\
\hline & & 8 & 60.42 & 68.42 & 51.66 & & \\
\hline & \multirow{4}{*}{ PFC } & 2 & 41.01 & 43.01 & 17.22 & \multirow{4}{*}{8.16} & \multirow{4}{*}{38.7} \\
\hline & & 4 & 47.57 & 51.57 & 31.71 & & \\
\hline & & 6 & 53.87 & 59.87 & 42.27 & & \\
\hline & & 8 & 61.13 & 69.13 & 51.68 & & \\
\hline
\end{tabular}

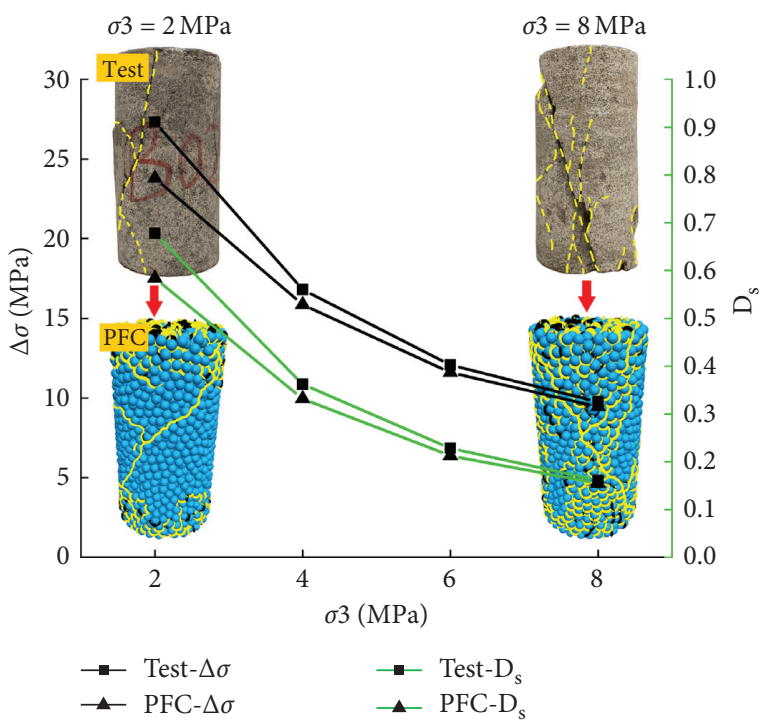

(a)

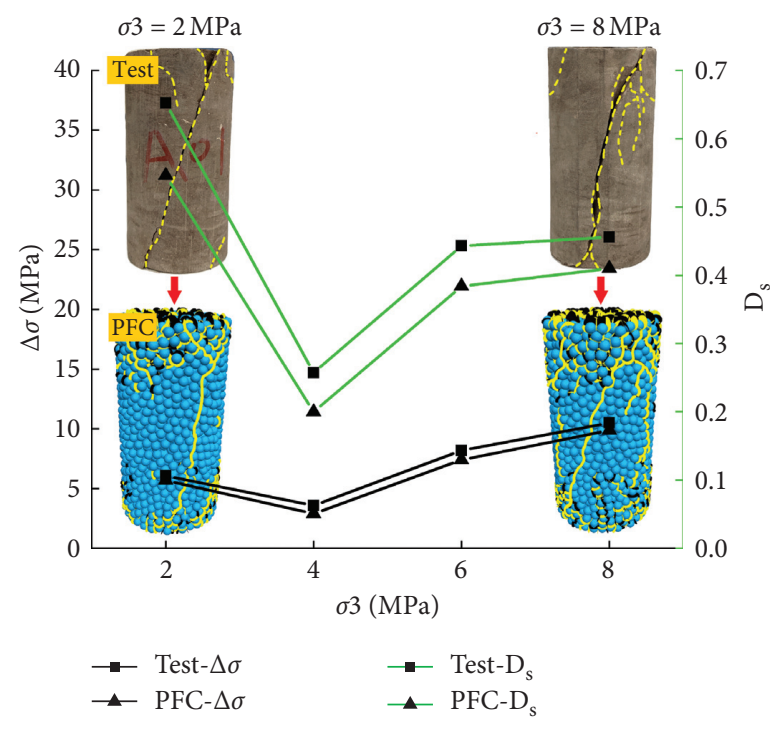

(b)

FIGURE 7: Comparison of rock attenuation value $\Delta \sigma$, attenuation coefficient $D_{s}$, and failure characteristics. (a) Sandstone. (b) Mudstone.

having fewer shear failure cracks and being characterized by obvious brittleness. The mudstone sample also recorded a few tension cracks from the base upwards. When the confining pressure increased to $8 \mathrm{MPa}, \mathrm{mi}-$ croscopic cracks at the base and top gradually increased, propagating towards the middle. At this time, shear failure of mudstone cracks increased and became more obvious. The failure characteristics and strength attenuation law of the two kinds of rocks in the indoor test and the PFC test were basically the same, adhering to the law proposed by Chen [32]. Therefore, rationality of the material mesoscopic parameters was further verified.

2.4.2. Triaxial Cyclic Loading Test and $\beta$-Parameter. The sandstone cyclic triaxial test dynamic stress-strain curve and its failure characteristics (Figure 8) indicate that, under the action of dynamic circulation, the peak stress intensity of the sandstone was obviously lower than that of the conventional triaxial. This result indicates that the compressive strength of the sandstone was weakened under dynamic load. Sandstone without cracks has instantaneous elastic deformation at the moment of loading, and its strain value is generally between 0 and $0.2 \%$; the strain value of sandstone with cracks is between 0 and $0.1 \%$. Under a certain confining pressure, sandstone gradually exhibits obvious creep properties as load applied by stepwise loading increases. Eventually, under the action of the last level of load, the sandstone appeared to be destroyed by an accelerated creep stage. Our results indicate that as the confining pressure increased, the number of loading levels also increased. As the confining pressure increased from 0 to $6 \mathrm{MPa}$, the axial load increased when creep failure occurred. As the increase of confining pressure 

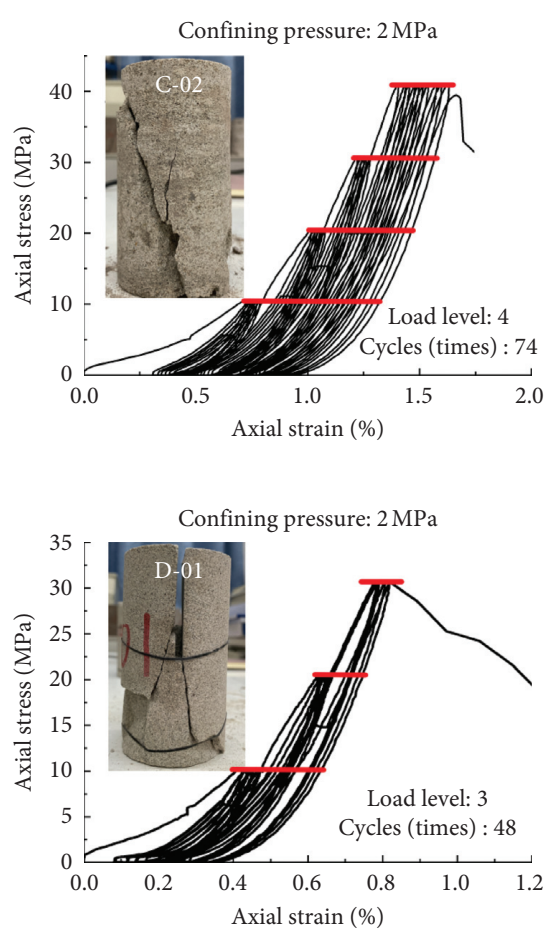

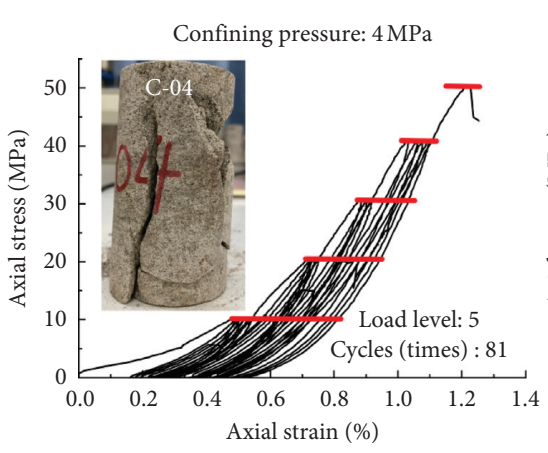

(a)

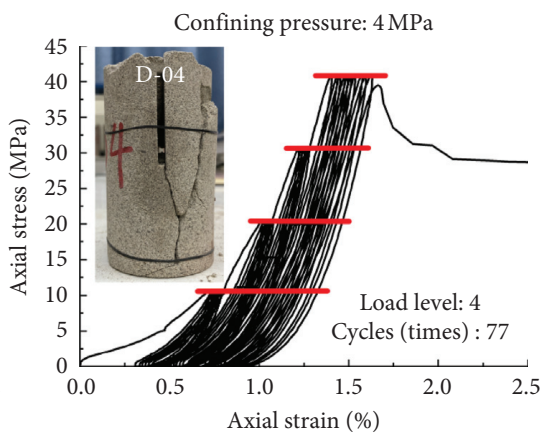

(b)
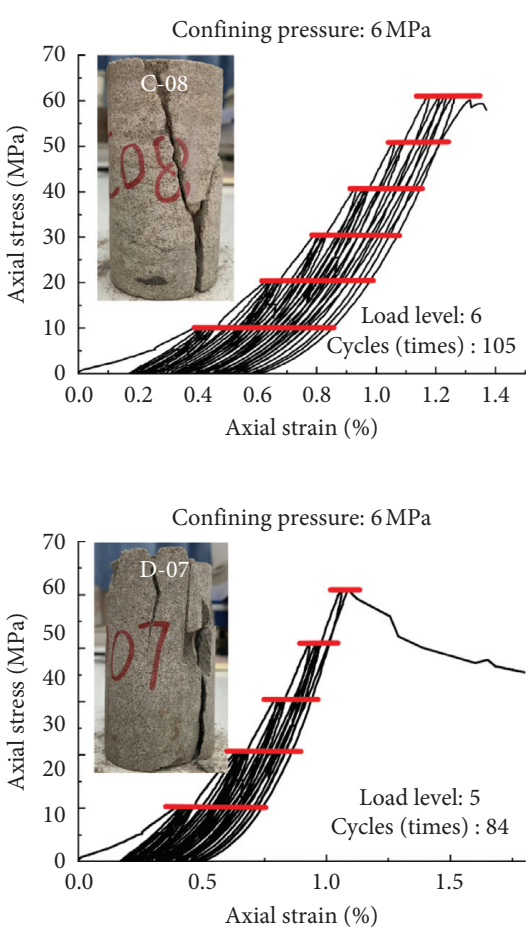

FIgURE 8: Cyclic triaxial dynamic stress-strain curve and failure characteristics. (a) Sandstone without cracks. (b) Sandstone with cracks.

improved the compressive strength of the sandstone, the occurrence of cracks resulted in the axial strain of the sandstone to increase. Under a confining pressure of $2 \mathrm{MPa}$, the number of cycles of sandstone with fractures was 36 times lower than that of sandstone without fractures, and the maximum peak stress declined by $10 \mathrm{MPa}(25 \%)$. At a confining pressure of $4 \mathrm{MPa}$, the number of cycles of sandstone with fractures was reduced by four times compared with sandstone without fractures, and the maximum peak stress was reduced by $10 \mathrm{MPa}(20 \%)$. At a confining pressure of $6 \mathrm{MPa}$, the number of cycles of sandstone with fractures was 31 times lower than that of sandstone without fractures, and the maximum peak stress declined by $10 \mathrm{MPa}$ $(16.7 \%)$. This result indicates that while the confining pressure increased, the yield strength of sandstone with fractures was one lower than that of sandstone without fractures, and it was more prone to failure under dynamic loads.

Analysis of failure characteristics indicates that sample C-02 has low confining pressure, low compressive strength, and low creep, and the sample is accompanied by partial tensile failure and primarily shear failure. As the confining pressure increased, the number of cycles increased stepwise and creep increased. Samples C-04 and C-08 recorded obvious simultaneous effects of tension and shear. In addition, tensile crack penetrated the entire sample, intersecting with the shear crack to form a Y-shaped crack in C-08. Results for cracked sandstone (Figure $8(\mathrm{~b})$ ) indicate that, when the low confining pressure is cyclically loaded, the crack expands outwards in the form of a tensile crack along with the reserved fracture, finally intersecting with the shear crack and failing.

In the cyclic loading stage, the damping ratio $\beta$ and the damping coefficient $C$ of the rock sample changed, and the condition of the cracks will affect $\beta$ and $C$ of the sandstone. By using equations (4) and (5), $\beta$ and $C$ were calculated. In order to facilitate the analysis of the influence of cracks on damping parameters, two sets of hysteresis loops with different cracks under a high confining pressure of $6 \mathrm{MPa}$ were selected to calculate $\beta$ and $C$. Finally, the relationship between the damping parameters of the two sets of sandstone samples and the number of cycles was calculated (Figure 9).

Results in Figure 9 indicate that, under the same confining pressure, the damping coefficient $C$ increases linearly with an increase in the number of cycles, and it is not affected by the increase of the load amplitude. In addition, the damping coefficient $C$ of sandstone with fractures is five times lower than that of sandstone without fractures. The damping ratio $\beta$ noticeably fluctuates under the action of cyclic loading with a confining pressure of $6 \mathrm{MPa}$, gradually decreasing as the number of cycles increases. The $\beta$ of fractured sandstone is generally $0.1 \%$ lower than that of sandstone without fractures. Under a higher confining pressure, the damping coefficient $C$ varies with cycle times in the opposite direction to the damping ratio $\beta$. This law is consistent with the results of Zhou [29], indicating that cracks have a degrading effect on the damping coefficient $C$ of sandstone. 


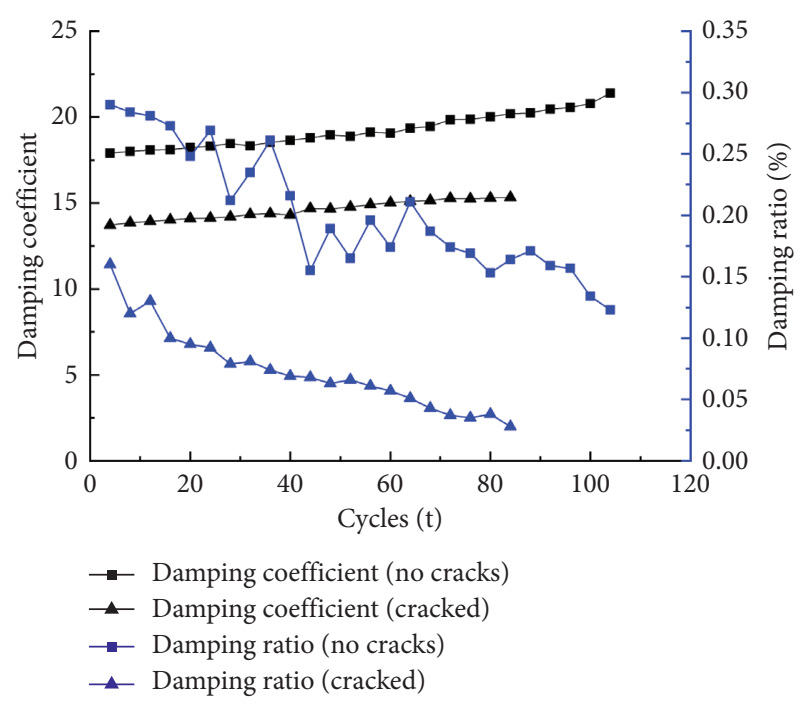

FIGURE 9: A $6 \mathrm{MPa}$ confining pressure on the sandstone damping coefficient, the damping ratio, and the number of cycles.

2.4.3. $\beta$ Mesoparameter Sensitivity Analysis. Results in Section 2.4.1 indicated that the attenuation value and attenuation coefficient of mudstone were relatively low in numerical experiments; results for sandstone were relatively high. This is because during the trial adjustment of the mesoparameters, those that affect rock brittleness mainly depend on the critical damping ratio $\beta$. The critical damping of mudstone is relatively low, and its brittleness is low in numerical tests; as the critical damping of sandstone is relatively high, it is therefore more brittle. Based on these conclusions, the following sensitivity analysis of $\beta$-mesoparameters of sandstone and mudstone was carried out.

(1) $\beta_{n}$-parameter sensitivity analysis: during the numerical triaxial test, under a constant confining pressure of $8 \mathrm{MPa}$ with other bonding mesoparameters unchanged, normal critical damping ratio $\beta_{n}$ of $0,0.1,0.2,0.3,0.4,0.5$, $0.6,0.7,0.8,0.9$, and 1.0 was used. Under different $\beta_{n}$ values, the stress-strain curves of mudstone and sandstone materials were calculated (Figure 10).

Results indicate that $\beta_{n}$ has an important influence on the peak strength of deviatoric stress of mudstone and sandstone. When $\beta_{n}$ had a value of 0 to 1.0 , the stress-strain curves of the two materials recorded an obvious "threesegment" distribution, and the curve trend was different. For mudstone, the increase of $\beta_{n}$ resulted in peak deviatoric stress and residual stress to increase; results for strain recorded no significant influence. When $\beta_{n}$ was $0,0.1,0.5$, $0.6,0.7,0.8$, and 1.0 , the peak deviatoric stress of mudstone was the largest, being 10-12 MPa larger than the peak deviator stress under actual mudstone parameters. This result demonstrates that the value of $\beta_{n}$ has an amplifying effect on the peak deviatoric stress of mudstone. When the $\beta_{n}$ value was 0.2 and 0.3 , the peak deviatoric stress and initial deviatoric stress of mudstone were moderate and consistent with the deviatoric stress under actual parameters, and the difference range was within $2 \mathrm{MPa}$. This indicates that the mesoscopic parameters of mudstone under $\beta_{n}$ are the closest to the actual effect. When the $\beta_{n}$ value was 0.4 and 0.9 , the strength of mudstone material was the lowest, and the peak deviatoric stress and initial deviatoric stress were $10-12 \mathrm{MPa}$ lower than the actual value. The $\beta_{n}$ value has a degrading effect on the strength of mudstone, and the initial deviatoric stress direction is abnormal, making the initial deviatoric stress value negative.

For sandstone, an increase in $\beta_{n}$ reduced overall peak deviatoric stress and residual stress. The peak strain fluctuated slightly under different $\beta_{n}$ values, and peak strain was the largest when $\beta_{n}$ was 0.3 . Considering the strength range, when $\beta_{n}$ was $0.1,0.4$, and 0.9 , the peak deviatoric stress of sandstone was the largest, being $5-6 \mathrm{MPa}$ larger than the peak deviatoric stress under actual sandstone parameters, and the initial deviatoric stress was also larger than the actual one. This result indicates that the $\beta_{n}$ value has an amplification effect on the peak deviatoric stress of sandstone, and the amplification value was within $10-12 \mathrm{MPa}$. When $\beta_{n}$ was 0.2 and 0.3 , the initial deviatoric stress and peak deviatoric stress of sandstone were closest to the actual value. Although the error was within $2 \mathrm{MPa}$, the strain was larger than the actual value. When adjusting these parameters, it is recommended that after these values are tested and adjusted, other mesoparameters need to be considered to continue to improve the strain calibration. When $\beta_{n}$ was $0.5,0.6,0.7$, and 1.0 , the peak deviator stress was too small. In the same way, the $\beta_{n}$ parameter under this condition had a degrading effect on sandstone and, with abnormal initial conditions, it is not recommended to be used in parameter sensitivity test adjustments.

For the process of judging whether the particle flow rock material is close to the real material, only using the peak stress and the values of $c$ and $\varphi$ as the judgment basis is not recommended. Rock ductility and brittleness should also be considered. Based on this, we also considered the sensitivity of $\beta$-parameters under the intensity attenuation value and intensity attenuation coefficient. The influence of $\beta_{n}$ parameter on material brittleness (Figure 11) indicates that, within the range $0-0.3$, the strength attenuation value of sandstone is $12-15 \mathrm{MPa}$ larger than that of mudstone, and a slight upward " $U$ "-shaped fluctuation occurs with the attenuation coefficient. Here, the $\beta_{n}$-parameter has little effect on the strength attenuation value and attenuation coefficient of the two materials, that is, the brittleness and ductility of the material remain unchanged. When $\beta_{n}$ increased to 1.0, the intensity attenuation value and attenuation coefficient significantly fluctuated as the damping ratio increased. The attenuation value of sandstone increased to $42.24 \mathrm{MPa}$ when $\beta_{n}$ had a value of 0.4 , and the attenuation coefficient increased to 0.68 . At this time, the mudstone attenuation value did not fluctuate. This result indicates that the $\beta_{n}$ value greatly improved the brittleness of the two kinds of rocks, and sandstone was more sensitive. When $\beta_{n}$ reached 0.5 , the attenuation value of sandstone significantly dropped to 22.19 MPa (the attenuation coefficient dropped to 0.52); the attenuation value of mudstone began to increase to 25.63 $\mathrm{MPa}$, and the attenuation coefficient decreased. Although this result shows that $\beta_{n}$ at this moment had greatly improved the ductility of sandstone and decreased its brittleness, its sensitivity to mudstone was not high. By 

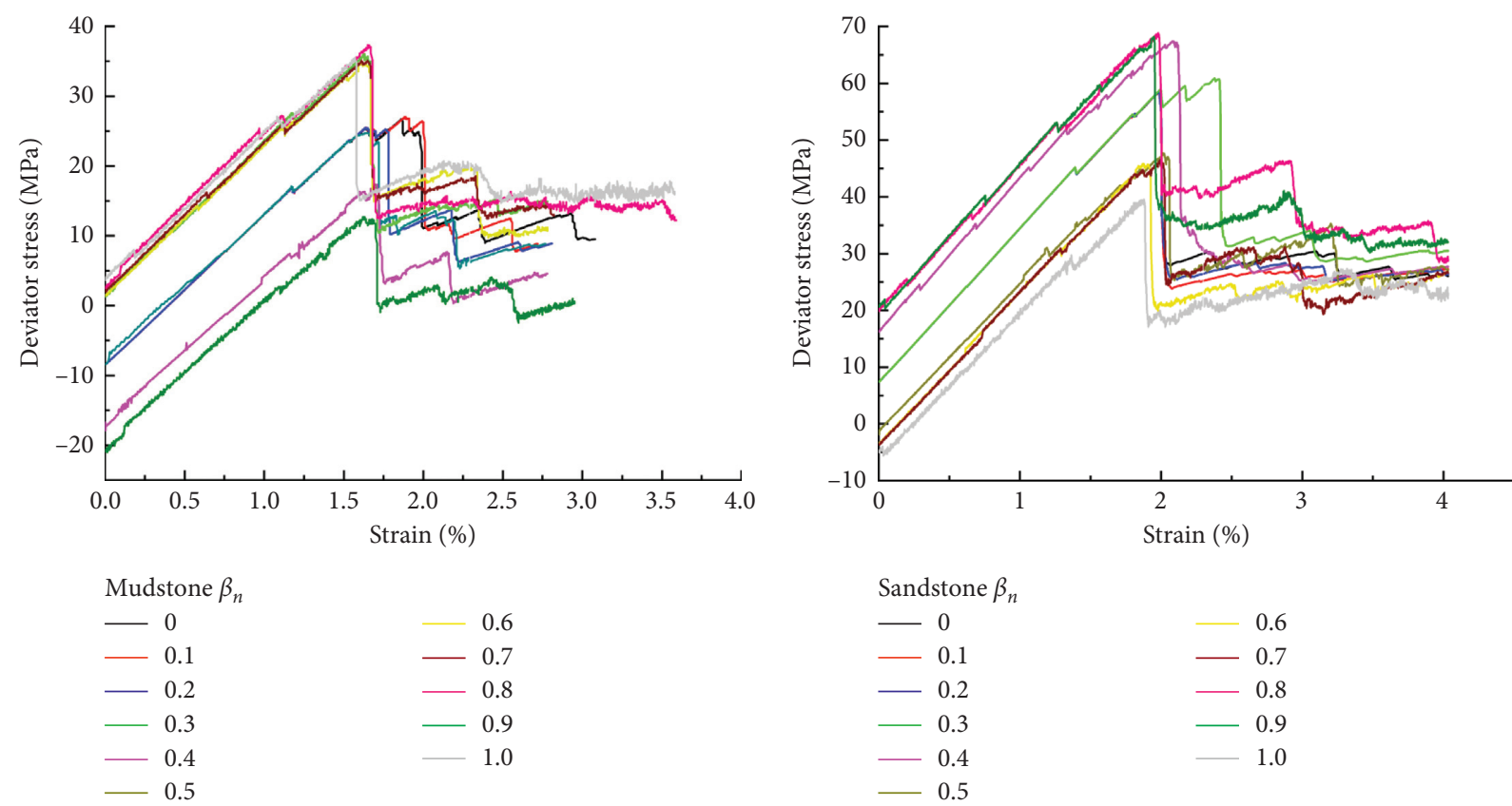

(a)

(b)

FIgURE 10: Two kinds of rock stress-strain curves under different $\beta_{n}$. (a) Mudstone. (b) Sandstone.

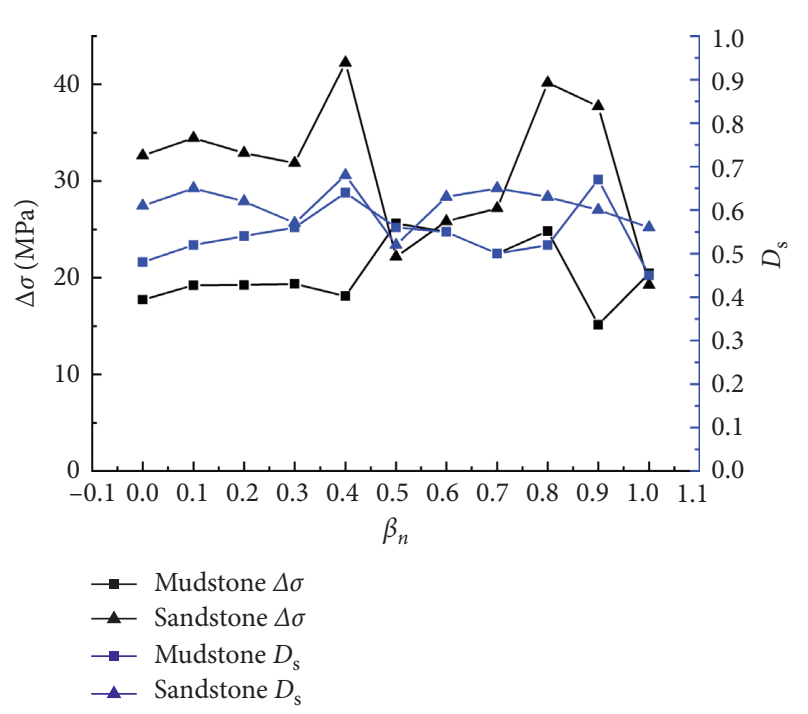

FIgURE 11: Intensity attenuation $\Delta \sigma$ and intensity attenuation coefficient $D_{s}$ of the two rocks under different $\beta_{n}$.

taking all of our results into consideration, brittleness of the two rock materials was relatively stable when the $\beta_{n}$ value was $0-0.3$ and the parameter value ranged between 0 and 1.0. At the same time, the trial adjustment of the $\beta_{n}$-parameter between 0.2 and 0.3 was closer to the actual value, and the macroscopic mechanical properties were more stable.

(2) $\beta_{s}$-parameter sensitivity analysis: as for the sensitivity analysis of the normal critical damping ratio $\beta_{n}$, confining pressure was maintained at $8 \mathrm{MPa}$ and other bonding mesoparameters were unchanged during $\beta_{\mathrm{s}}$-parameter sensitivity analysis. The shear critical damping ratio $\beta_{s}$ was taken as 0 , $0.1,0.2,0.3,0.4,0.5,0.6,0.7,0.8,0.9$, and 1.0 (Figure 12).
As seen in Figure 12, the peak deviatoric stress of mudstone and sandstone materials did not significantly change with an increase in $\beta_{s}$, and it was consistent with the deviatoric stress under the actual macroscopic test. This result indicates that the shear damping ratio had no great influence on the macroscopic yield strength of the two materials, and there was no need to consider its influence on the peak deviatoric stress during the mesoscale trial adjustment. The influence of $\beta_{s}$-parameter on material brittleness is shown in Figure 13.

$\beta_{s}$-parameter had a certain influence on the brittleness of the two rock materials. For mudstone, the strength attenuation value and attenuation coefficient showed a "wave-shaped" change as $\beta_{s}$ increased. When $\beta_{s}$ was 0.1 , the maximum attenuation value and attenuation coefficient reached $19.33 \mathrm{MPa}$ and 0.54 , respectively, and the minimum attenuation value and attenuation coefficient were $15.1 \mathrm{MPa}$ and 0.43 when $\beta_{s}$ was 0.7 , respectively. In the process of parameter trial adjustment, the range can be set within $0.1 \sim 0.7$, and the selection was based on the strength attenuation coefficient obtained from the indoor test. For sandstone, as $\beta_{s}$ increased, the strength attenuation curve recorded an "arch" change. When the $\beta_{s}$ value was 0.2 , the brittleness of sandstone increased from 0.53 to 0.65 before remaining stable; when $\beta_{s}$ was 0.6 , brittleness decreased to 0.53 . According to the attenuation coefficient obtained from the indoor test, it was observed that the $\beta_{s}$-parameter was within the range of 0.2 to 0.6 as a reasonable and sensitive test adjustment range. At this time, brittleness of the sandstone material was closest to the real material.

2.4.4. Mesoparameter Calibration. Based on the above quantitative and qualitative analysis, the final mesoparameters of mudstone and sandstone materials are shown 

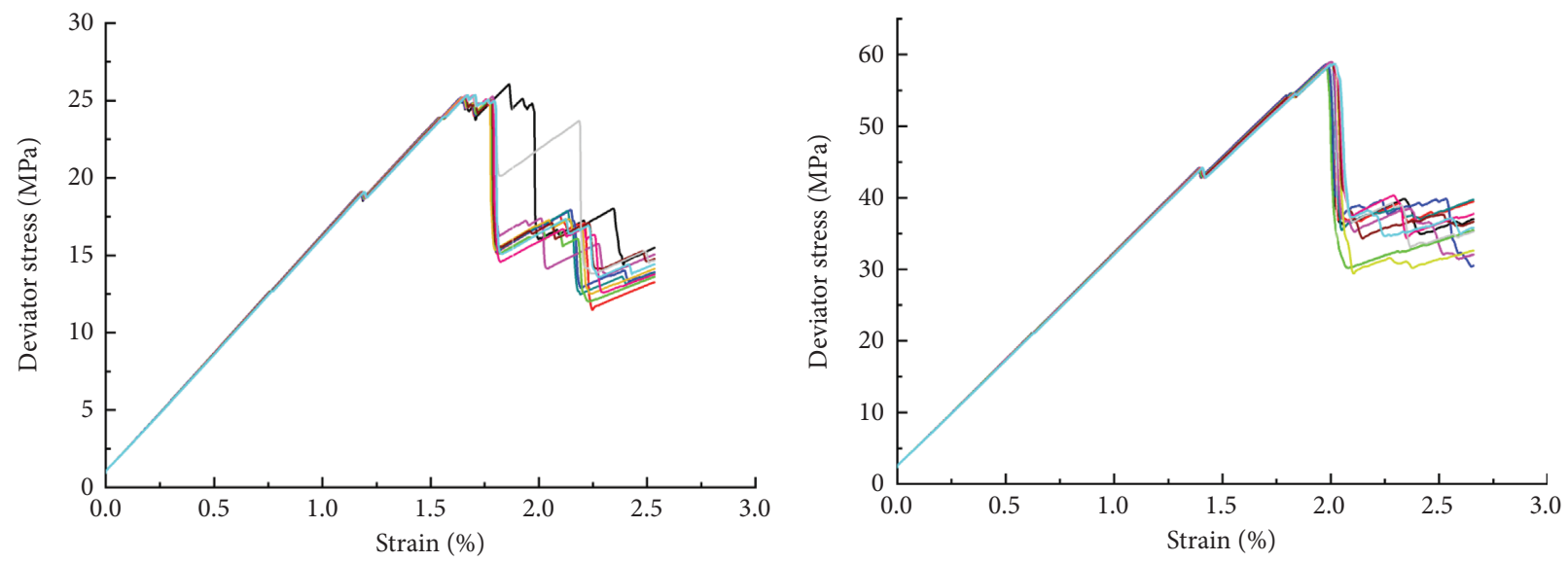

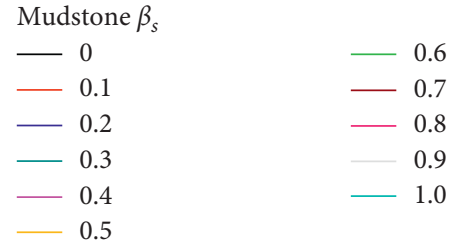

(a)

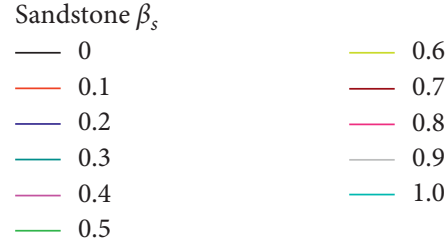

(b)

Figure 12: Mudstone (a) and sandstone (b) stress-strain curves under different $\beta_{s}$ values.

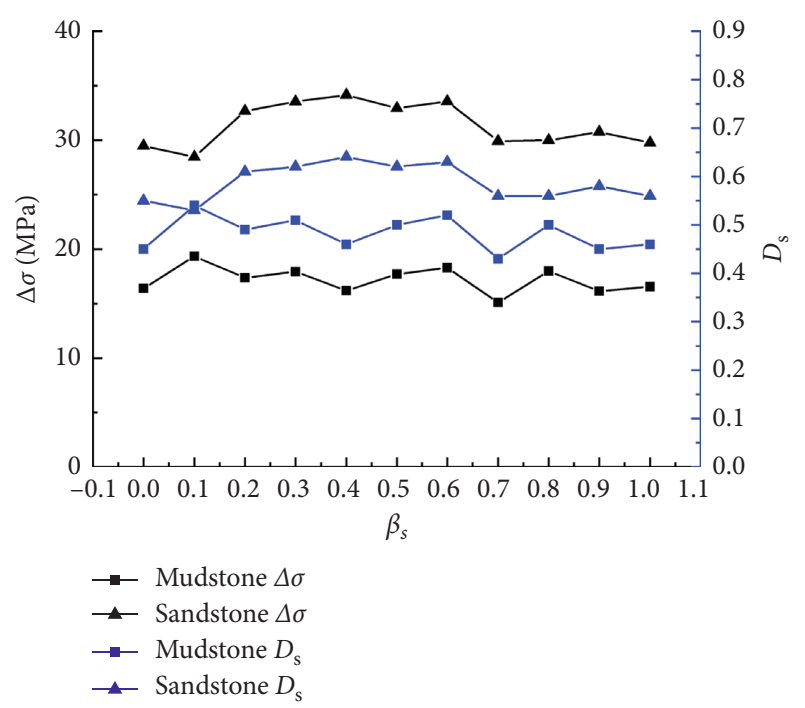

FIGURE 13: Intensity attenuation $\Delta \sigma$ and intensity attenuation coefficient $D_{s}$ of the two rocks under different $\beta_{s}$ values.

in Table 2. With reference to previous studies [33, 34], the structure of surface mesoparameters (Table 3) was confirmed.

\section{Dangerous Rock Model}

3.1. Model Establishment. In this study, we used a typical steep slope of dangerous rock on Provincial Highway 205, Beichuan Qiang Autonomous County, Sichuan Province, China (Figure 14), as a case study. The 2008 Wenchuan Earthquake in Sichuan caused a series of instabilities, resulting in the collapse of dangerous rocks posing a significant threat to the safe operation of the provincial highway and nearby residents. After a detailed geological survey, the steep slope of dangerous rock (about $23 \mathrm{~m}$ high) was restored. The upper rock mass is composed of feldspar sandstone with good integrity, about $16 \mathrm{~m}$ high, with a natural bulk density of $24.7 \mathrm{~kg} / \mathrm{m}^{3}$ and a fracture toughness of $26.0 \mathrm{MPa} \mathrm{m}^{1 / 2}$; the lower rock mass is mudstone with poor integrity, being about $7 \mathrm{~m}$ high with a natural bulk density of $25.3 \mathrm{~kg} / \mathrm{m}^{3}$. The fracture penetration rate is $25 \%$, and four sandstone layers were identified in the rock mass, including two main control structural planes. According to the chain law of rock slope [35], the external macrochain was called the No. 1 chain, and the internal macrochain was the No. 2 chain. Each macrochain contains four microchains, and the dangerous rock masses are numbered from bottom to top (the first chain was $1-1,1-2,1-3$, and 1-4, and the second chain was 2-1, 2-2, 2-3, and 2-4).

According to survey results of on-site dangerous rocks, reasonable generalizations were made for this investigation. PFC3D was used to establish a particle flow model for dangerous rock slopes in three dimensions (Figure 15). Here, the formation of the rock joint surface adopted artificial synthetic rock mass technology [36], and the linear parallel bond model was selected as the internal contact model of the rock; the smooth-joint contact model was the contact model of the joint surface between the rocks.

The seismic model under the coupling action of transverse waves and longitudinal waves has an amplifying effect on stability, and the probability of both acting at the same point at the same time is small. It was therefore decided to use the first $20 \mathrm{~s}$ acceleration curve (Figure 16) of the real EW transverse wave monitored in Wolong during the 
TABLE 2: Mesoscopic parameters of sandstone and mudstone materials.

\begin{tabular}{lcccccccccccc}
\hline Lithology & $d(\mathrm{~mm})$ & $\mathrm{P}\left(\mathrm{kg} \cdot \mathrm{m}^{-3}\right)$ & $E_{c}(\mathrm{GPa})$ & $K c^{*}$ & $\mu$ & $\lambda$ & $K^{*}$ & $E_{b}(\mathrm{GPa})$ & $\sigma_{c}(\mathrm{MPa})$ & $c(\mathrm{MPa})$ & $\beta_{n}$ & $\beta_{s}$ \\
\hline Mudstone & 0.24 & 3100 & 2 & 1.0 & 0.8 & 1.00 & 1.0 & 20 & 18 & 28 & 0.2 & 0.2 \\
Sandstone & 0.26 & 3000 & 3 & 1.0 & 0.6 & 1.01 & 1.0 & 30 & 20 & 35 & 0.3 & 0.6 \\
\hline
\end{tabular}

Table 3: Mesoscopic parameters of the structural plane.

\begin{tabular}{|c|c|c|c|c|c|}
\hline Structural plane type & $\mathrm{sj} \_\mathrm{kn}\left(\mathrm{N} \cdot \mathrm{m}^{-1}\right)$ & $\mathrm{sj}_{-} \mathrm{k}_{\mathrm{s}}\left(\mathrm{N} \cdot \mathrm{m}^{-1}\right)$ & $s j \_\mu$ & $s j_{\_} c(\mathrm{MPa})$ & $s j_{-} \varphi\left(^{\circ}\right)$ \\
\hline Horizontal structure plane & 10 & 1 & 0.7 & 0.3 & 10 \\
\hline Vertical structural plane & 10 & 1 & 0.3 & 0 & 8 \\
\hline
\end{tabular}

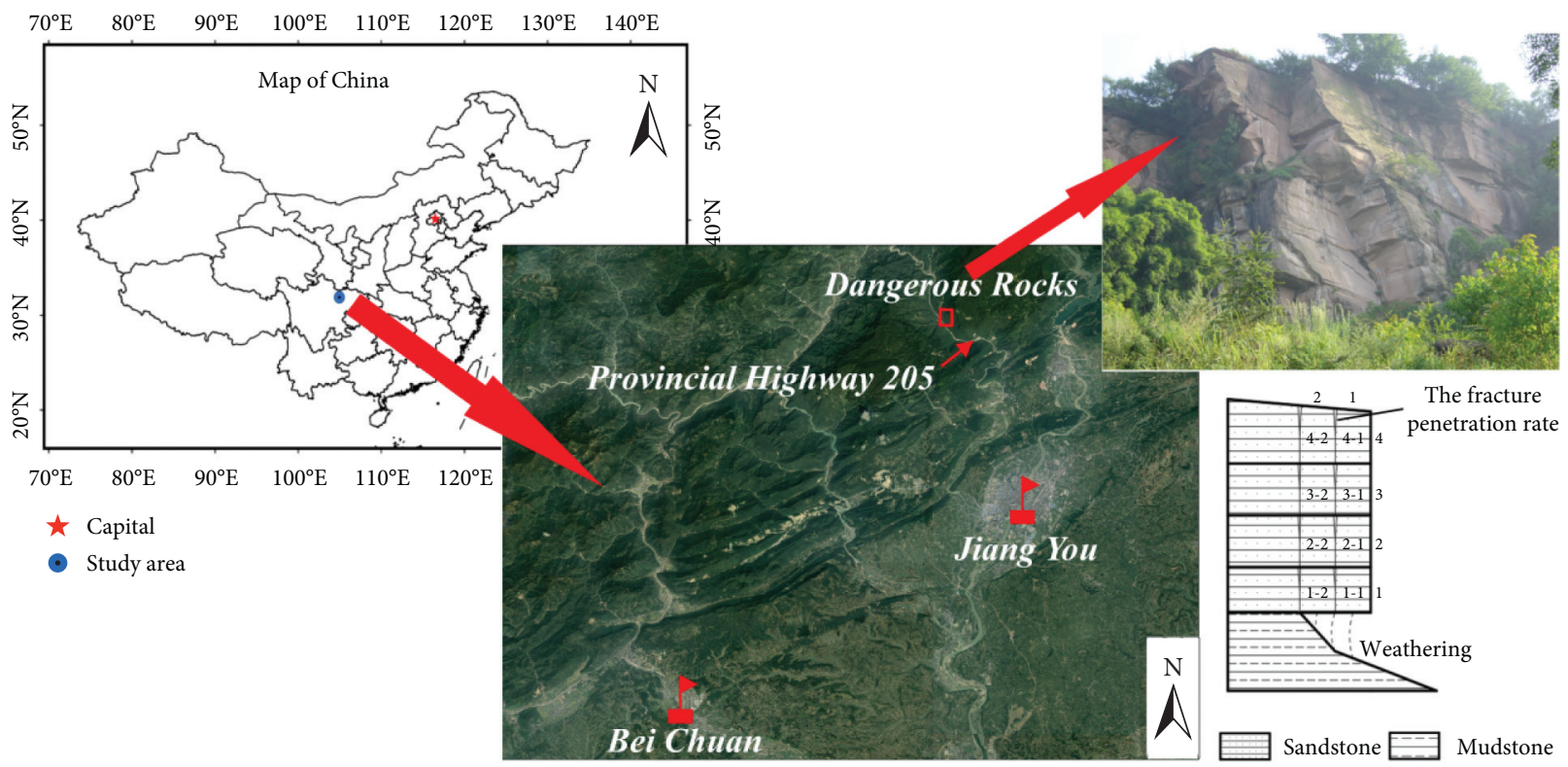

FIgure 14: Damaged rock on Provincial Highway 205, Beichuan Qiang Autonomous County, Sichuan Province, China.

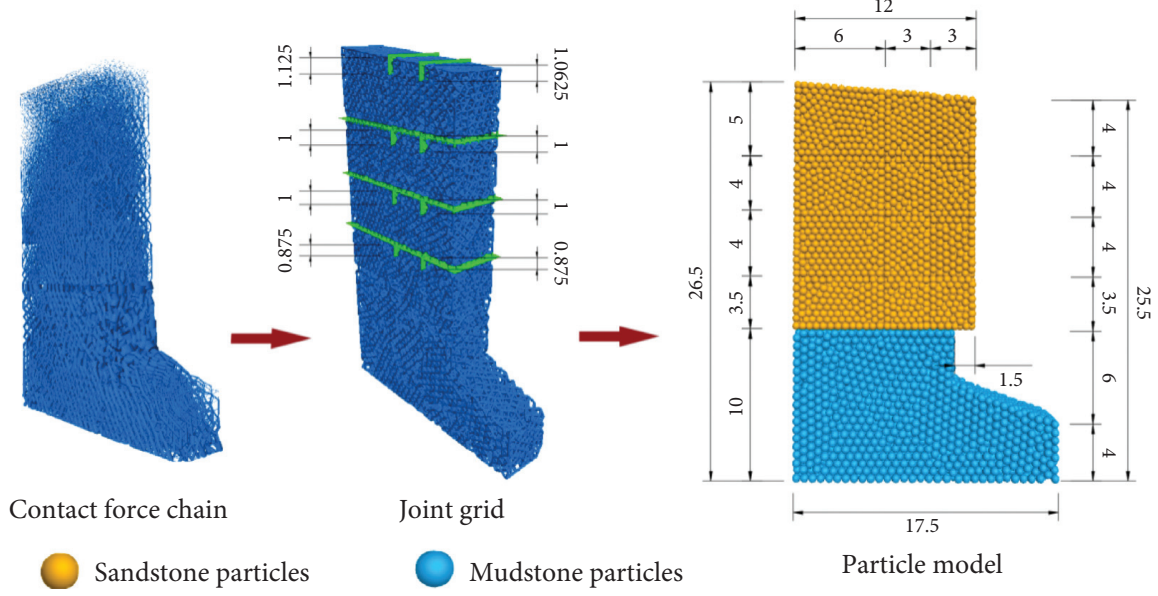

FigURE 15: Slope force chain and joint grid layout (unit: m).

Wenchuan earthquake as the seismic input. When applying seismic action, in order to prevent seismic waves from reflecting at the boundary of the model, a viscous boundary condition is required [37]. In PFC3D, this was achieved by setting dampers in the normal and tangential directions of the two sides and the bottom boundary of the model, as 


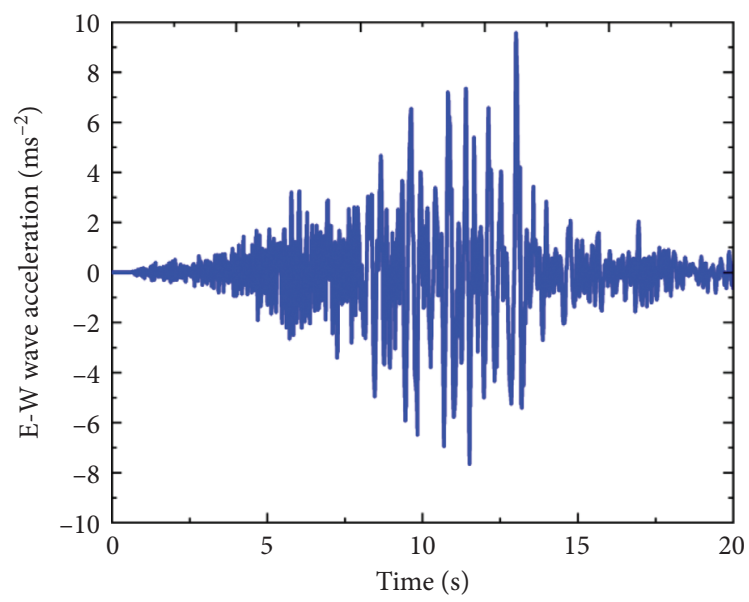

FIGURE 16: E-W wave acceleration-time history curve.

shown in Figure 17. During the loading process, seismic acceleration was transformed into boundary acceleration, resulting in the model particles to vibrate.

\subsection{Seismic Damage Analysis of Dangerous Rock Model}

3.2.1. Failure Mode Analysis. The destruction process of the dangerous rock model under a $20 \mathrm{~s}$ earthquake is shown in Figure 18. Model results indicate that, between a seismic shear wave time of 0 and $6 \mathrm{~s}$, the rock mass did not undergo significant deformation or damage. At the same time, crack development in the lower mudstone was not recorded and slope stability was generally good. Comparison with the particle velocity cloud map indicated that the maximum particle movement velocity was concentrated on the bottom rock mass 1-1 and rock mass 1-2 at $3 \mathrm{~s}$. At $6 \mathrm{~s}$, the maximum particle velocity was transferred to the second and third layers of rock, indicating that, before the rock mass was destroyed, the failure trend was concentrated between the first and third layers. When calculation time reached $9 \mathrm{~s}$, the seismic acceleration curve gradually peaked (see Figure 8). Here, the internal structural surface contact model of Nos. 11, 2-2, and 3-2 dangerous rocks was locally fractured, and cracks in rock mass 1-2 gradually developed. Approximately $10 \mathrm{~s}$ later, the 1-2 rock mass fractured. In addition, the top rock layer began to move, accompanied by the fracture of the smooth joint model between the layers. The particle velocity at this moment was the largest relative to the velocity at other moments, and the failure trend was concentrated between the first and third rock mass layers. When the earthquake rupture time was $11.5 \mathrm{~s}$, the internal vertical rock mass fell outward as a whole, colliding with the external vertical rock mass, being pulled apart. Because of this movement, fissures between the rock masses were further enlarged. In addition, due to gravity and seismic action of the upper rock mass, particles in the lower mudstone base began to disintegrate. At $20 \mathrm{~s}$, due to the interaction of adjacent rock blocks at the bottom under the earthquake, the top rock block (No. 4-1) broke locally. As this rock block was located on the lower rock mass, it therefore fluctuated with the earthquake. At the

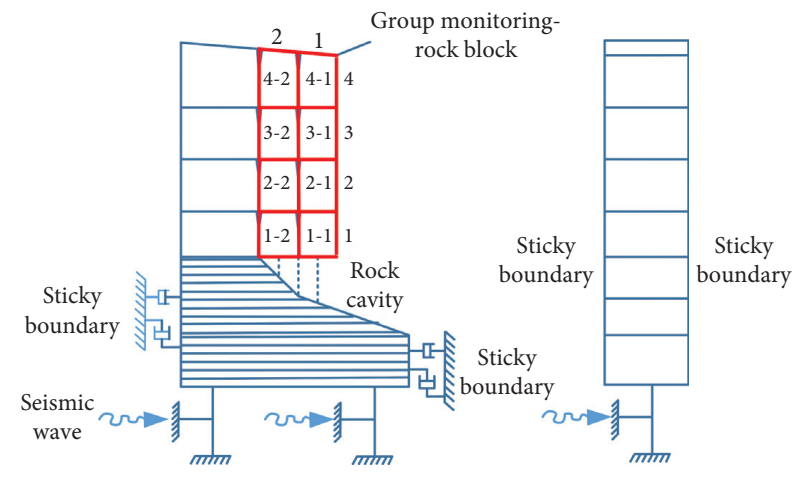

Figure 17: Boundary conditions for the dynamic calculation.

same time, the rest of the rock masses, except for No. 4-2, had a tendency to bulge outwards as a whole. However, based on the support of the upper and lower rock masses, no rock mass collapse occurred. In summary, the dangerous rock of Provincial Highway 205 in the high-intensity area will undergo slight instability failure under the action of a traverse EW-wave $20 \mathrm{~s}$ strong earthquake, and the failure mode will be a tensile fracture-horizontal slip failure.

In order to further verify the rationality of the rock material mesoparameters and the seismic damage of the PFC dangerous rock model, we introduced two other dangerous rock failure maps in the area (Figure 19). It can be seen that after the Wenchuan earthquake, the failure mode of the real dangerous rock was basically consistent with the failure mode of the earthquake simulated in our study.

3.2.2. Displacement Analysis. Monitoring the vertical and horizontal displacement of the rock block in this study provides further information on the failure mode and stability of the rock block. Model displacement in the vertical $z$-direction and horizontal $y$-direction (Figure 20) indicate that there is no sign of rock collapse or falling during the earthquake action period; the displacement value was recorded to be very small. Negative vertical displacement (distributed between 0 and $0.4 \mathrm{~m}$ ) and 


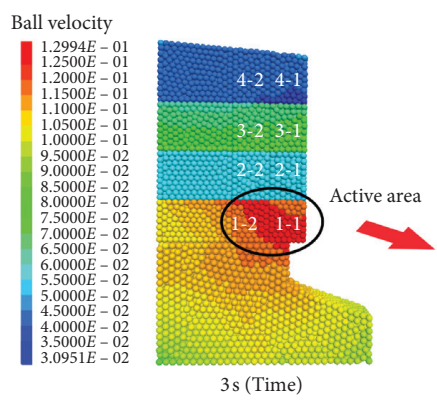

3s (Time)

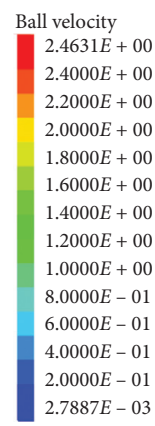

$2.7887 E-03$

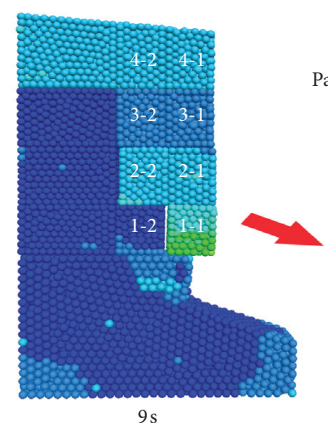

(b)
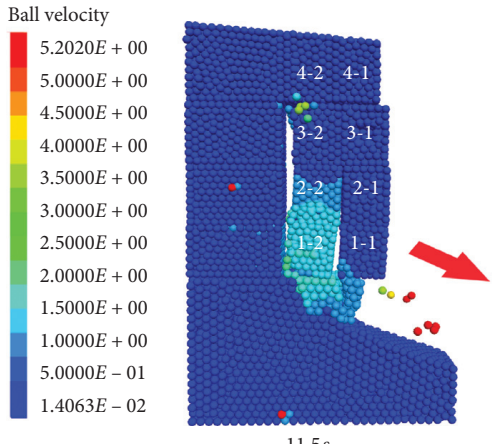

$11.5 \mathrm{~s}$

(d)

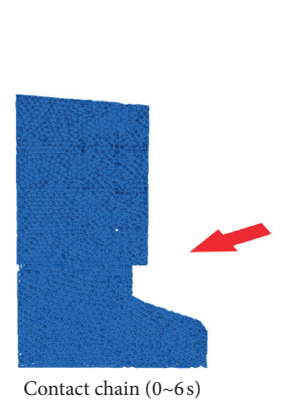

(a)
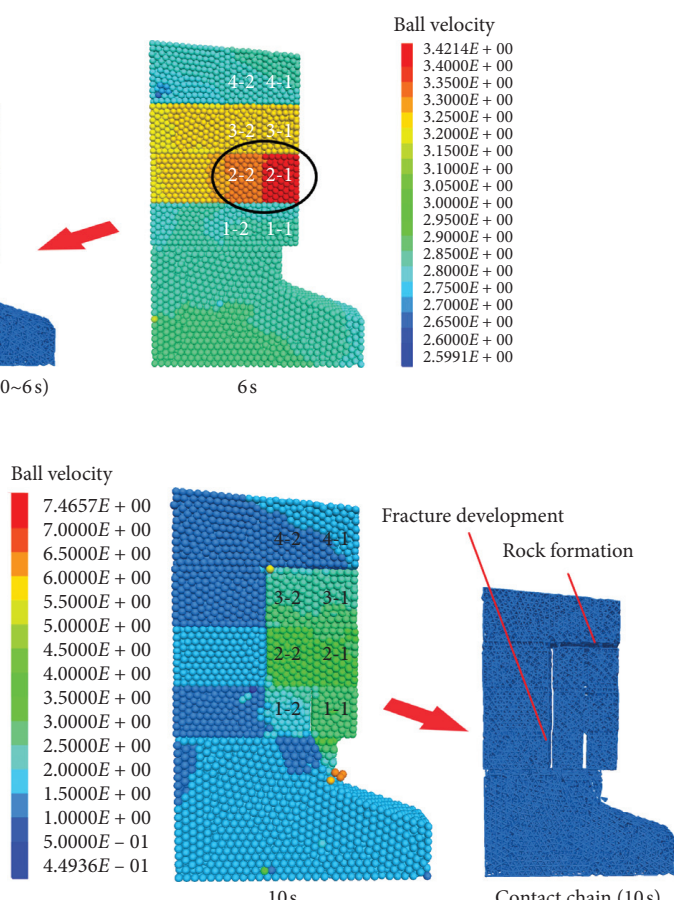

(c)

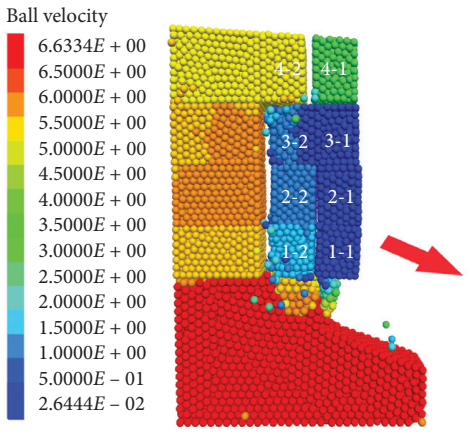

20 s
Contact chain (11.5s)

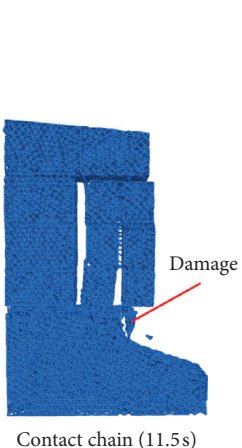

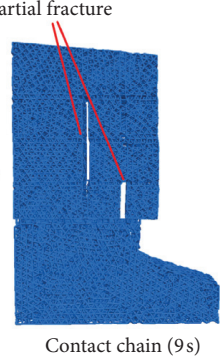

(e)

FIGURE 18: The failure process of the dangerous rock model under different earthquake durations. (a) $0 \sim 6 \mathrm{~s}$, (b) $9 \mathrm{~s}$, (c) $10 \mathrm{~s}$, (d) $11.5 \mathrm{~s}$, and (e) $20 \mathrm{~s}$.

positive horizontal displacement (distributed between 0 and $1.2 \mathrm{~m}$ ) values indicate that the failure characteristics of the model in the vertical and horizontal directions are small, and the impact of earthquakes in the horizontal direction is relatively large. No vertical displacement change was recorded between 0 and $9 \mathrm{~s}$ in the calculation time. In addition, the particles of each rock block all have horizontal $y$-direction displacement fluctuations with the action of shear waves, and the amplitude of the fluctuations increases as seismic action time extended. During this period, there was also no sign of damage to the slope, indicating a stable state. After $8.5 \mathrm{~s}$, displacement of each rock block in Model 1 fluctuated with a small frequency in the vertical direction before slowly declining after $11 \mathrm{~s}$. At this time, horizontal displacement to the right gradually increased, with a maximum value of $1.2 \mathrm{~m}$ distributed in the top rock block No. 4-1. After the calculation, displacement in both directions of the 1-1 rock block continued to increase, and the vertical and horizontal displacement curves of the remaining rock blocks tended to be flat. Results in Figure 18 indicate that the rock block was damaged and fractured during this period. Although the mudstone base cracked and stability gradually decreased, caving and rolling failure did not occur. Based on the damage trend, it can be judged that rock blocks 4-1 and 1-1 will be the most likely to fall. It should be noted that the vertical displacements of No. 1-2 and No. 3-2 rock masses are large, possibly due to adjacent rock masses colliding and squeezing each other, resulting in surface rock mass particles to break and fall off.

3.2.3. Analysis of Unbalanced Force of the Rock Block. By analyzing the failure modes of various slope models under earthquake conditions, it is accepted that the dynamic interaction of rock blocks is an important factor causing rock 


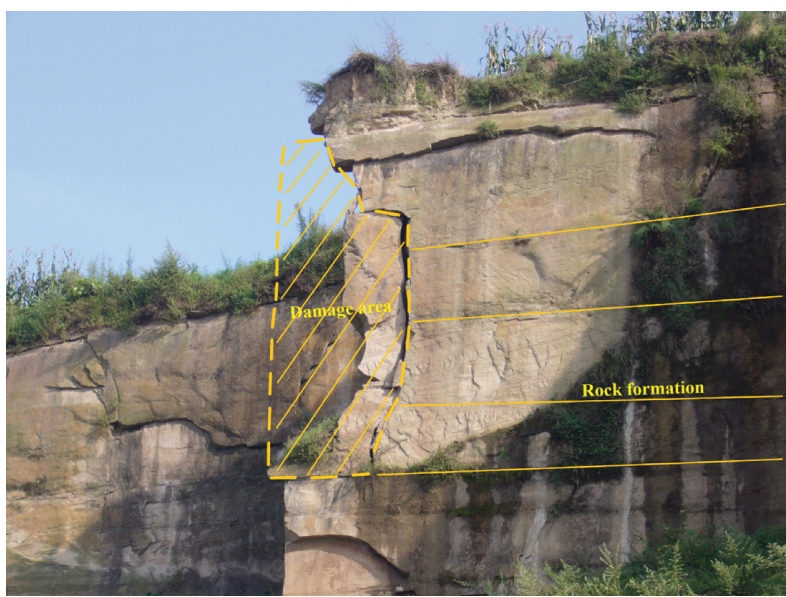

(a)

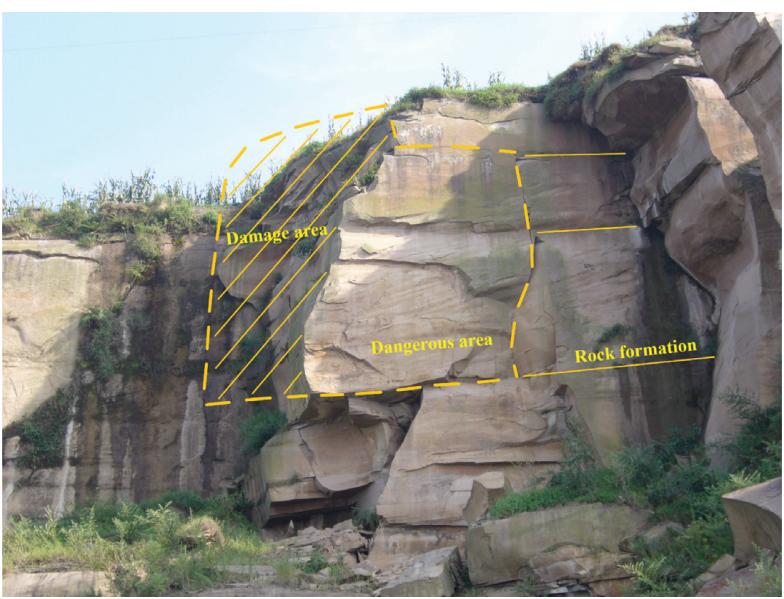

(b)

FIgURE 19: On-site destruction of \#3 and \#4 dangerous rock slopes. (a) \#3. (b) \#4.

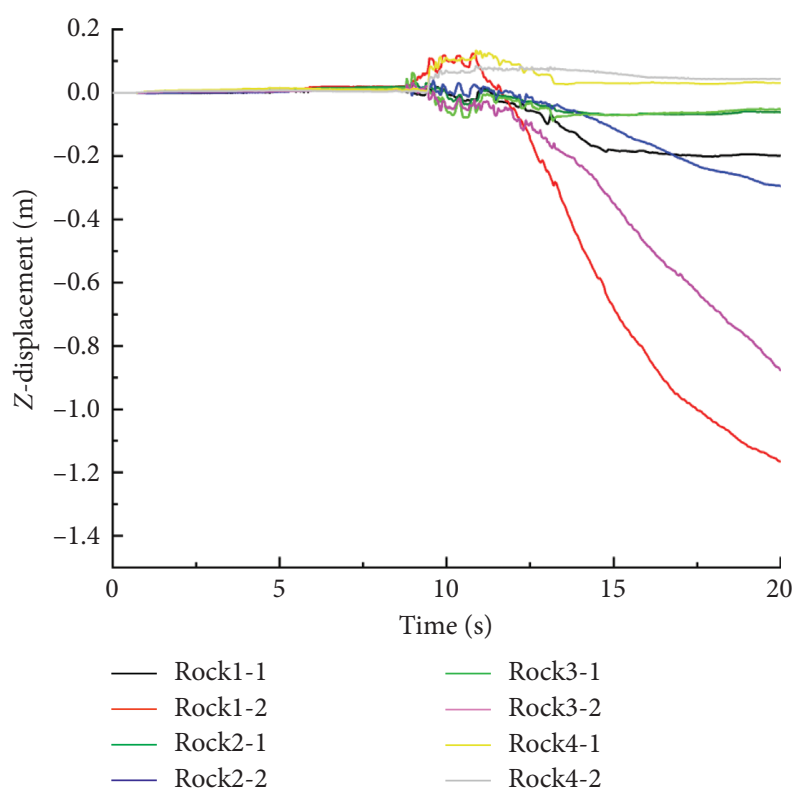

(a)

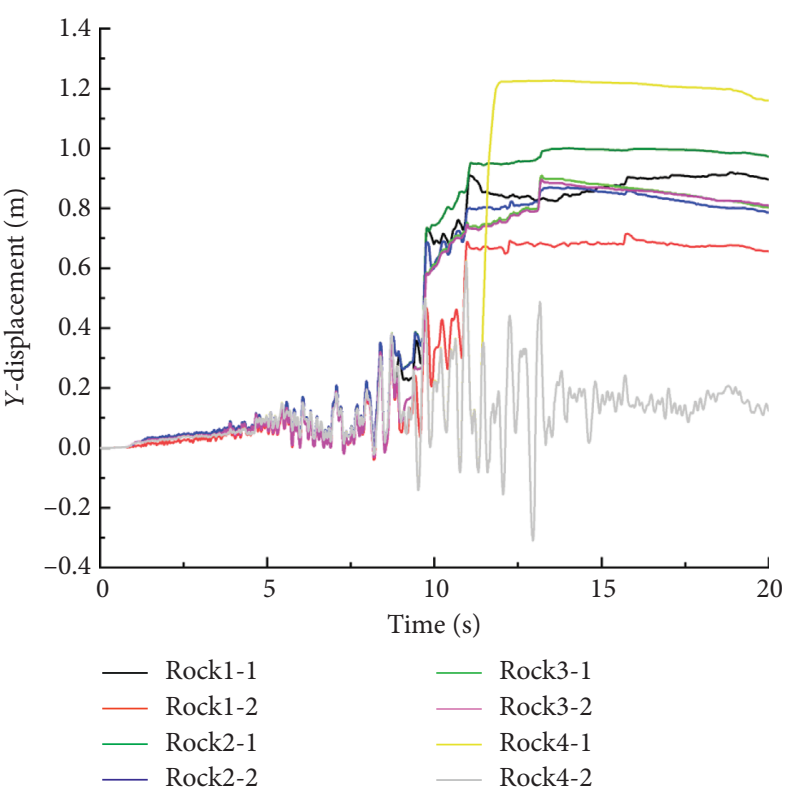

(b)

Figure 20: Time history curve of model displacement. (a) Vertical $z$-direction displacement. (b) Horizontal $y$-direction displacement.

mass collapse. In PFC, the unbalanced force of the particle not only represents the size of the contact force chain around the particle but also includes the tension and compression of the interlayer load and adjacent rock blocks. Therefore, the unbalanced force in each rock block can represent the magnitude and direction of the load on each rock block. The unbalanced force fluctuation curve of each rock block, obtained using in situ monitoring, is shown in Figure 21. In the vertical $z$-direction, the rock mass unbalanced force predominantly fluctuates between 8 and 13 seconds. This wave phenomenon is caused by rocks caving and colliding with each other. The vertical upward peak unbalanced force generated by the fracture was $230 \mathrm{kN}$, generated by rock block 4-1; the vertical downward peak unbalanced force was $350 \mathrm{kN}$, generated by rock blocks 1-2 and 3-2. The maximum horizontal $y$-direction unbalanced force was distributed in rock blocks 1-2, and the peaks were concentrated in the maximum seismic acceleration interval. It can be seen that 


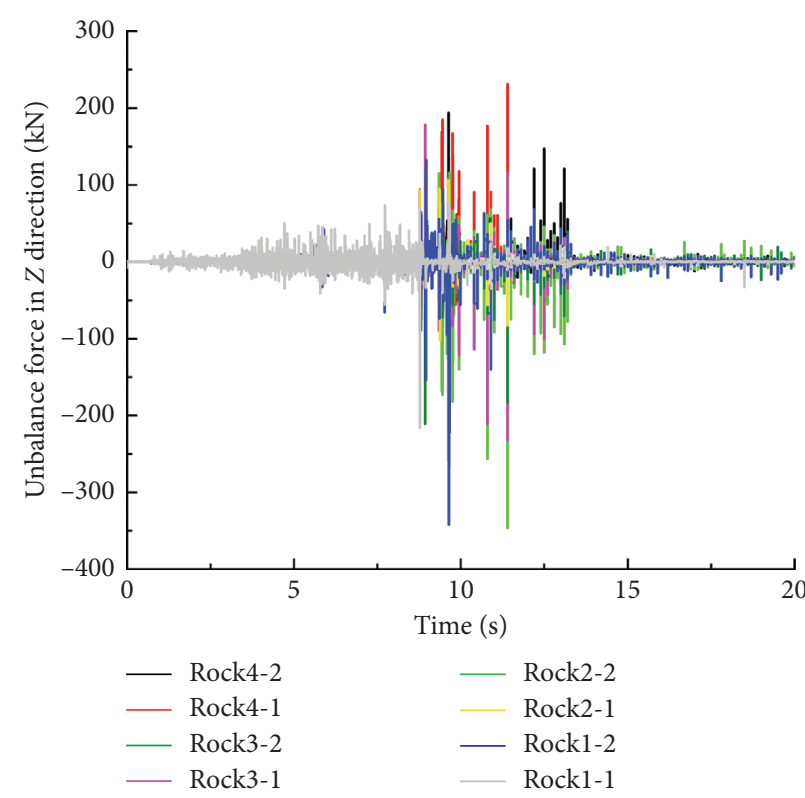

(a)

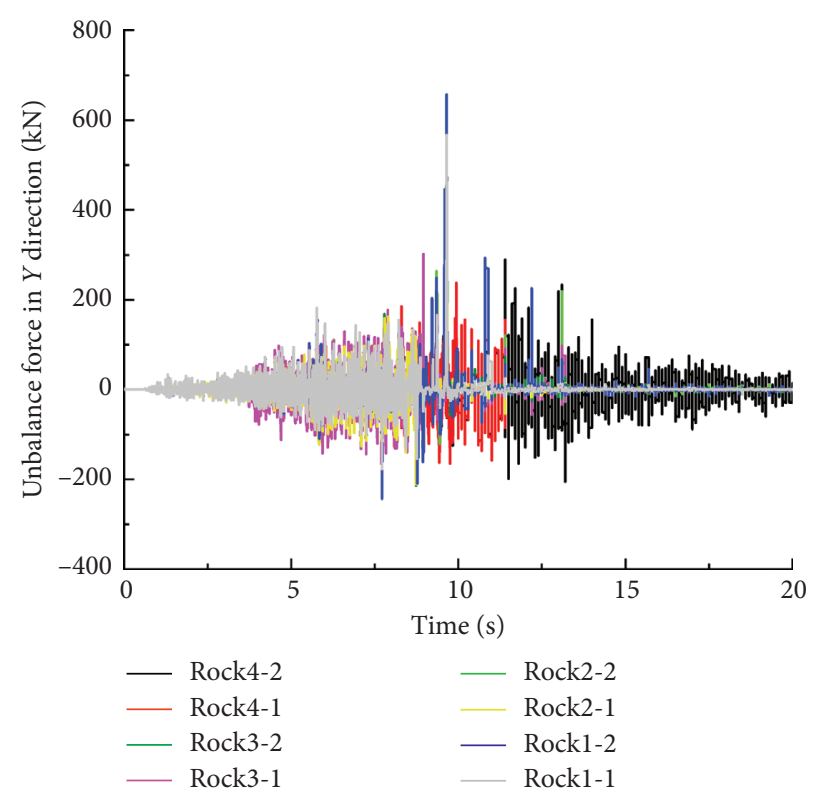

(b)

FIGURE 21: Time history curve of unbalanced force. (a) Vertical $z$-direction. (b) Horizontal $y$-direction.

collisions of Nos. 4-1, 1-2, and 3-2 rock blocks are the most violent under the action of an earthquake, especially rock block 1-2.

\section{Conclusions}

Based on the principle of discrete element particle flow, we conducted an in-depth analysis of the mechanical characteristics and mesoparameters ( $\beta$-parameters) of rock materials through dynamic and static triaxial tests of sandstone and mudstone. Findings from this investigation enhance the reliability of rock material mesoparameter calibration technology. Furthermore, a more realistic and reliable dangerous rock model compared to previous studies was presented, with seismic stability analysis undertaken. Conclusions from this study are as follows:

(1) The brittleness of sandstone gradually weakened with an increase in confining pressure, with brittleness weakening more severely after a confining pressure of $2 \mathrm{MPa}$. In addition, the characteristic value of mudstone brittleness attenuation recorded a V-shaped change with increasing confining pressure. Under low confining pressure, the brittleness of mudstone was preferentially weakened and ductility was enhanced. Under high confining pressure, the brittleness of mudstone was enhanced and ductility decreased. During the PFC numerical three-axis test, mudstone particles were recorded to undergo shear failure and the sandstone particles underwent tensile failure. The failure characteristics of the two types of rocks in the PFC numerical test are in accordance with results from an indoor test.

(2) Fissures have a degrading effect on $\beta$ and $C$ of sandstone. When the rock fails, the dynamic compressive strength of sandstone with cracks is one lower than that of sandstone without cracks. The peak stress of the compressive strength of the former is reduced by $16.7 \%$ 25\% compared with the latter. This finding indicates that sandstone, especially sandstone with many cracks, is more prone to damage under dynamic load. Under the same confining pressure, the damping coefficient increases linearly with the increase of the number of cycles, and it is not affected by the increase of the loading amplitude. The damping coefficient of sandstone with fractures is generally lower than that of sandstone without fractures by a factor of five.

(3) During the trial adjustment of mesoparameters, the peak deviatoric stress and $c-\varphi$ value are not the only criteria for judging the authenticity of materials. The effect of material brittleness is equally important to mesoparameters and cannot be ignored. In addition, the mesoparameters of rock brittleness mainly depend on the damping ratio $\beta$. Mudstone has a relatively low $\beta$ and low brittleness whereas sandstone has a high $\beta$ and high brittleness. In rock materials, $\beta_{n}$ is more sensitive than $\beta_{s}$. The value of the $\beta_{n}$-parameter was between 0.2 and 0.3 , and the value of $\beta_{s}$-parameter was between 0.2 and 0.6 . Rock brittleness was more stable and the reflected macroscopic mechanical properties were more realistic. With an increase of $\beta_{s}, \Delta_{s}$ and $D_{s}$ of mudstone indicated "wave-shaped" changes. In contrast, sandstone recorded "arch" changes.

(4) After an in-depth analysis of mesoparameters, the failure mode of the PFC dangerous rock model of Provincial Highway 205 under the simulated Wenchuan earthquake was a tensile fracture-horizontal 
slip failure. The simulated failure mode was basically consistent with results recorded for the real dangerous rock. Combined with displacement analysis, the failure trend was concentrated between the first layer to the third layer of the rock mass. The failure characteristics of the model in the vertical and horizontal directions were small, and the horizontal influence was relatively large. In addition, the dangerous rock did not eventually collapse and fall in a large area. It is judged that rock blocks 4-1 and 1-1 are likely to fall in the later stage of an earthquake. Combined with analysis of the unbalanced force, collisions of rock blocks 4-1, 1-2, and 3-2 are the most violent under the action of the earthquake, especially rock block 1-2.

\section{Data Availability}

The table and figure data used to support the findings of this study are available from the corresponding author upon request.

\section{Conflicts of Interest}

The authors declare that they have no conflicts of interest.

\section{Acknowledgments}

This work was financially supported by the National Key Research and Development Project (2016YFC0802203), National Natural Science Foundation (51678097), Science and Technology Research Project of Chongqing Municipal Education Commission (KJQN201800706), and the General Project of Chongqing Natural Science Foundation (cstc2020jcyj-msxmX0218). The authors would like to express their gratitude to EditSprings (https://www. editsprings.com/) for the expert linguistic services provided.

\section{References}

[1] L. F. Wang, H. M. Tang, and F. Tang, "Three-dimensional stability analysis of complex gently inclined rock mass slope," China Journal of Highways, vol. 31, pp. 57-66, 2018.

[2] A. Azzon, G. La Barbera, and A. Zanietti, "Analysis and prediction of rockfalls using a mathematical model," International Journal of Rock Mechanics and Mining Sciences and Geomechanics Abstracts, vol. 32, pp. 709-724, 1995.

[3] H. K. Chen, "Geomorphological Interpretation of the chain law of dangerous rocks in the three gorges reservoir area," Journal of Chongqing Jiaotong University (Natural Science Edition), vol. 27, pp. 91-94, 2008.

[4] H. M. Tang, H. K. Chen, and L. F. Wang, "Study on mechanism of dangerous rock caving on rocky steep slope," Metal Mine, vol. 392, pp. 40-45, 2009.

[5] H. M. Tang, H. K. Chen, and L. F. Wang, "Dangerous base collapsed cliff on a dangerous base," Geotechnical Engineering, vol. 3, pp. 205-210, 2010.

[6] G. Z. Yan, C. Jie, and S. Yu, "Earthquake response and sliding displacement of submarine sensitive clay slopes," Engineering Geology, vol. 227, pp. 69-83, 2017.
[7] X. F. Huang, Y. B. Zhang, and X. Q. Zhao, "Preliminary discussion on the movement characteristics of dangerous rock collapse under earthquake conditions," Rock and Soil Mechanics, vol. 38, pp. 583-592, 2017.

[8] K. Zhao, Y. W. Zeng, and C. Zeng, "Stability analysis of rock slope with weak structural surface based on particle flow method," Science Technology and Engineering, vol. 18, pp. 97-102, 2018.

[9] C.-L. Tang, J.-C. Hu, M.-L. Lin, R.-M. Yuan, and C.-C. Cheng, "The mechanism of the 1941 Tsaoling landslide, Taiwan: insight from a 2D discrete element simulation," Environmental Earth Sciences, vol. 70, no. 3, pp. 1005-1019, 2013.

[10] Y. Cong, Z. Q. Wang, and Y. R. Zheng, "Experimental study on microscopic parameters of brittle materials based on particle flow theory," Chinese Journal of Geotechnical Engineering, vol. 37, pp. 1031-1040, 2015.

[11] M. M. He, N. Li, and W. S. Chen, "Damping ratio and damping coefficient of rock under different cyclic loading conditions," Rock and Soil Mechanics, vol. 38, pp. 2531-2538, 2017.

[12] Y. H. Huang, S. Q. Yang, and Y. Ju, "Experimental study on mechanical behavior of rock-like materials containing preexisting intermittent fissures under triaxial compression," Chinese Journal of Geotechnical Engineering, vol. 38, pp. 1212-1220, 2016.

[13] J. Zhou, Y. X. Wang, and Y. F. Zhou, "Macro-micro evolution mechanism on sandstone failure in triaxial compression test based on PFC2d," Journal of China Coal Society, vol. 42, pp. 76-82, 2017.

[14] Z. C. Tang and Y. B. Zhang, "Temperature-dependent peak shear-strength criterion for granite fractures," Engineering Geology 2020, vol. 269, Article ID 105552, 2020.

[15] Z. C. Tang, Q. Z. Zhang, and J. Peng, "Effect of thermal treatment on the basic friction angle of rock joint," Rock Mechanics and Rock Engineering, vol. 53, no. 4, pp. 1973-1990, 2020.

[16] Z. C. Tang, "Experimental investigation on temperature-dependent shear behaviors of granite discontinuity," Rock Mechanics and Rock Engineering, vol. 53, no. 9, pp. 40434060, 2020.

[17] Z. Tang and Y. Jiao, "Choosing appropriate appraisal to describe peak-spatial features of rock-joint profiles," International Journal of Geomechanics, vol. 20, no. 4, Article ID 4020021, 2020.

[18] J. Zou, Y.-Y. Jiao, Z. Tang, Y. Ji, C. Yan, and J. Wang, "Effect of mechanical heterogeneity on hydraulic fracture propagation in unconventional gas reservoirs," Computers and Geotechnics 2020, vol. 125, Article ID 103652, 2020.

[19] L. J. Wang, Numerical Analysis on Characteristics of Reinforced Soil Retaining Wall Based on Particle Flow Code, Chongqing Jiaotong University, Chongqing, China, 2019.

[20] J. J. Tian and J. S. Sun, "Influence of spring and sticky kettle parameters on deformation features in particle flow numerical simulation of rock creep," Safety and Environmental Engineering, vol. 26, pp. 202-206, 2019.

[21] Y. H. Huang and S. Q. Yang, "Particle flow simulation of macro- and meso- mechanical behavior of red sandstone containing two pre-existing non-coplanar fissures," Chinese Journal of Rock Mechanics and Engineering, vol. 33, pp. 1644-1653, 2014.

[22] S. C. Wu, Y. Zhou, and B. Gao, "Study of unloading tests of rock burst and pfc3d numerical simulation," Chinese Journal of Rock Mechanics and Engineering, vol. 29, pp. 4082-4088, 2010. 
[23] L. Jin and Y. W. Zeng, "Refined simulation for macro-and meso-mechanical properties and failure mechanism of soilrock mixture by 3D DEM," Chinese Journal of Rock Mechanics and Engineering, vol. 37, pp. 1540-1550, 2018.

[24] Y. B. Deng, Y. P. Yang, and D. D. Shi, "Refinement and application of variable particle-size methods in 3D discrete element modelling for large-scale problems," Chinese Journal of Geotechnical Engineering, vol. 39, pp. 62-70, 2017.

[25] G. Zheng, X. S. Cheng, and Y. Diao, "Discrete element simulation and redundancy analysis of excavation collapse," Rock and Soil Mechanics, vol. 35, pp. 573-583, 2014.

[26] J. P. Zuo, Y. Cheng, and J. W. Zhang, "Failure behavior and strength characteristics of coal-rock assembly under different confining pressures," Journal of China Coal Society, vol. 41, pp. 2706-2713, 2016.

[27] J. F. Labuz and A. Zang, "Mohr-coulomb failure criterion," Rock Mechanics and Rock Engineering, vol. 45, no. 6, pp. 975-979, 2012.

[28] J. Peng, G. Rong, and M. Cai, "Determination of residual strength of rocks by a brittle index," Rock and Soil Mechanics, vol. 26, pp. 403-408, 2015.

[29] J. B. Zhou, Research on Dynamic Stability of Cracked Structure Rock Mass and Seismic Reinforcement in Strong Earthquake Zone, Chengdu University of Technology, Chengdu, China, 2012.

[30] J. Xu, Q. S. Li, and G. L. Li, "Experimental research on damping parameters of rock under cyclic loading," Chinese Journal of Rock Mechanics and Engineering, vol. 29, pp. 1036-1041, 2009.

[31] X. H. Cheng, "Discrete element analysis for size effects of coarse-grained soils," Rock and Soil Mechanics, vol. 30, pp. 287-292, 2009.

[32] Y. Chen, Study on Deformation Failure Behaviors and Nonlinear Models for Rocks under the Influence of Mining Disturbance, China University of Mining and Technology, Xuzhou, China, 2018.

[33] K. Bian, J. Liu, and X. J. Hu, "Study on failure mode and dynamic response of rock slopes with intermittent joints and intermittent joints under earthquake action," Rock and Soil Mechanics, vol. 39, pp. 3029-3037, 2018.

[34] X. J. Hu, K. Bian, and P. C. Li, "Particle flow simulation of seismic dynamic failure process of horizontal thick layered rock slope," Chinese Journal of Rock Mechanics and Engineering, vol. 36, pp. 2156-2168, 2017.

[35] H. K. Cheng and H. M. Tang, "Chained mechanism and moving routine for perilous rock toavalanche in the area of the three gorges reservoir of China," in Proceedings of China Association for Science and Technology, pp. 501-506, Beijing, China, January 2006.

[36] Z. Cui and Q. Sheng, "Numerical modelling of structural effect of equivalent mechanical parameters of fractured rock mass," Rock and Soil Mechanics, vol. 39, pp. 3830-3840, 2018.

[37] X. T. Zhou, Q. Sheng, and X. L. Leng, "Viscous artificial boundary for seismic dynamic time-history analysis with granular discrete element method and its application," Chinese Journal of Rock Mechanics and Engineering, vol. 36, pp. 928-939, 2009. 